\title{
Physiologically Based Pharmacokinetic Model Predictions of Panobinostat (LBH589) as a Victim and Perpetrator of Drug-Drug Interactions ${ }^{\mathbb{}}$
}

\author{
Heidi J. Einolf, Wen Lin, Christina S. Won, Lai Wang, Helen Gu, Dung Y. Chun, Handan He, \\ and James B. Mangold
}

Pharmacokinetic Sciences, Novartis Institutes for Biomedical Research, East Hanover, New Jersey

Received May 24, 2017; accepted September 12, 2017

\begin{abstract}
Panobinostat (Farydak) is an orally active hydroxamic acid-derived histone deacetylase inhibitor used for the treatment of relapsed or refractory multiple myeloma. Based on recombinant cytochrome P450 (P450) kinetic analyses in vitro, panobinostat oxidative metabolism in human liver microsomes was mediated primarily by CYP3A4 with lower contributions by CYP2D6 and CYP2C19. Panobinostat was also an in vitro reversible and time-dependent inhibitor of CYP3A4/5 and a reversible inhibitor of CYP2D6 and CYP2C19. Based on a previous clinical drug-drug interaction study with ketoconazole (KTZ), the contribution of CYP3A4 in vivo was estimated to be $\sim 40 \%$. Using clinical pharmacokinetic (PK) data from several trials, including the KTZ drug-drug interaction (DDI) study, a physiologically based pharmacokinetic (PBPK) model was built to predict panobinostat PK after single and multiple doses (within 2-fold of observed
\end{abstract}

values for most trials) and the clinical DDI with KTZ (predicted and observed area under the curve ratios of 1.8). The model was then applied to predict the drug interaction with the strong CYP3A4 inducer rifampin (RIF) and the sensitive CYP3A4 substrate midazolam (MDZ) in lieu of clinical trials. Panobinostat exposure was predicted to decrease in the presence of RIF (65\%) and inconsequentially increase MDZ exposure (4\%). Additionally, PBPK modeling was used to examine the effects of stomach $\mathrm{pH}$ on the absorption of panobinostat in humans and determined that absorption of panobinostat is not expected to be affected by increases in stomach $\mathrm{pH}$. The results from these studies were incorporated into the Food and Drug Administration-approved product label, providing guidance for panobinostat dosing recommendations when it is combined with other drugs.

\section{Introduction}

Panobinostat (Farydak, formerly LBH589) is an orally active hydroxamic acid-derived histone deacetylase (HDAC) inhibitor for the treatment of relapsed and refractory multiple myeloma (MM). Panobinostat was approved by the US Food and Drug Administration (FDA) and European Medicines Agency (EMA) as a combination therapy with bortezomib and dexamethasone (DEX) in patients with relapsed or refractory MM who have received at least two prior therapies containing an immunomodulatory agent and bortezomib. HDAC enzymes catalyze the deacetylation of lysine residues on histones and prevent the transcription of genes encoding proteins involved in cell-cycle regulation, differentiation, and apoptosis (reviewed in Garnock-Jones, 2015). Inhibition of HDAC enzymes by drugs like panobinostat causes an increase in histone acetylation, leading to cellular responses such as cell-cycle

http://doi.org/10.1124/dmd.117.076851

S This article has supplemental material available at dmd.aspetjournals.org. arrest, apoptosis, and delays in mitosis (reviewed in Cheng et al., 2015). The molecular structure of panobinostat is shown in Fig. 1.

Panobinostat is considered a biopharmaceutics classification system class I/II-like drug. In cancer patients, it is highly permeable and rapidly absorbed after an oral dose, with peak levels occurring within 2 hours (Farydak prescribing information, 2016; and FDA Clinical Pharmacology Review, 2015). The systemic clearance (CL) was estimated to be 33 liters/hour based on population pharmacokinetic (PK) analysis (Savelieva et al., 2015). There is a high first-pass CL with an absolute bioavailability of $\sim 21 \%$ (Farydak prescribing information, 2016). The absorption of panobinostat is altered when the drug is taken with a highfat meal ( $44 \%$ reduction in $C_{\max }$ and a delayed $T_{\max }$ of $1-1.5$ hours), but the area under the curve (AUC) is minimally impacted (Shapiro et al., 2012). Solubility of panobinostat lactate anhydrous is pH-dependent, with the highest solubility in buffer $\mathrm{pH} 3.0$ and low solubility at $\mathrm{pH} 7.6$ (Farydak prescribing information, 2016; FDA Clinical Pharmacology Review, 2015). Currently, no clinical studies have examined an increase of $\mathrm{pH}$ on the $\mathrm{PK}$ of panobinostat. In the radiolabeled human absorption,

ABBREVIATIONS: ACAT, advanced compartmental absorption and transit; ADME, absorption, distribution, metabolism, and excretion; AUC, area under the concentration-time curve; BNF, $\beta$-napthoflavone; $\mathrm{Cl}$, confidence interval; $\mathrm{CL}$, clearance; $\mathrm{CL}_{\text {int }}$, intrinsic $\mathrm{clearance} \mathrm{CL}_{\text {int,u}}$, unbound intrinsic clearance; $\mathrm{CL}_{\mathrm{R}}$, renal clearance; $\mathrm{C}_{\max }$, maximal concentration; $\mathrm{DDI}$, drug-drug interactions; DEX, dexamethasone; EMA, European Medicines Agency; $f_{\mathrm{a}}$, fraction of dose absorbed; FDA, Food and Drug Administration; $f u_{\text {gut }}$, unbound fraction in the gut; $f u_{\text {mic }}$, unbound fraction in microsomes; $f u_{\text {plasma }}$, unbound fraction in plasma; HDAC, hydroxamic acid-derived histone deacetylase; HLM, human liver microsomes; HPLC, high-performance liquid chromatography; $k_{\mathrm{a}}$, absorption rate constant; $K_{\mathrm{i}}$, inhibition constant; $K_{\mathrm{m}}$, Michaelis-Menten constant; $K_{\mathrm{m}}$, u unbound Michaelis-Menten constant (corrected by $f u_{\text {mic }}$ ); KTZ, ketoconazole; LC-MS/MS, liquid chromatography-tandem mass spectrometry; MM, multiple myeloma; P450, cytochrome P450; PB, phenobarbital; PBPK, physiologically based pharmacokinetics; $P_{\text {eff,man, }}$ effective permeability in man; PK, pharmacokinetics; $Q_{\text {gut }}$, nominal flow through the gut; RAF, relative activity factor; RIF, rifampin; $T_{\max }$, time to reach maximum concentration; $V_{\text {max }}$, maximum velocity; $V_{s s}$, volume of distribution at steady state. 


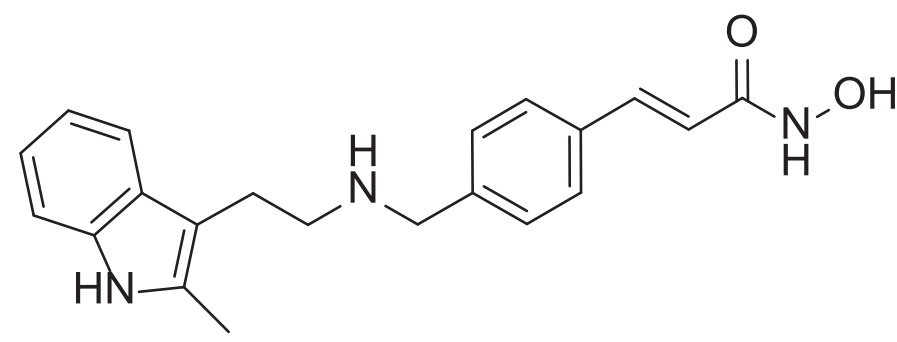

Fig. 1. The chemical structure of panobinostat.

disposition, metabolism, and excretion (ADME) study, 44\%-77\% of the oral $\left[{ }^{14} \mathrm{C}\right]$-panobinostat dose was recovered in the feces, and $29 \%-51 \%$ was excreted in urine (Clive et al., 2012). The main elimination pathway of panobinostat in humans was determined to be metabolism, as the mean unchanged panobinostat recovered in urine was only $1.9 \%$ of the dose and the presence of panobinostat in the feces was found in only one patient ( $\sim 3.3 \%$ of the dose). The minimal recovery of parent drug in feces suggested near-complete oral absorption of panobinostat. The metabolism of panobinostat was extensive in humans; at least 77 distinct metabolites were identified with $\sim 40$ observed circulating in plasma (Clive et al., 2012). The prominent metabolic pathways of panobinostat included reduction and hydrolysis of the hydroxamic acid and one- and twocarbon shortening of this side chain, as well as mono-oxygenation and glucuronidation. Based on the identity of the metabolites present in the excreta, cytochrome P450 (P450)-mediated oxidative CL was estimated to range from a maximum of $30 \%$ to $47 \%$ of the dose (Clive et al., 2012). These data were consistent with the resultant effect of the CYP3A4 strong inhibitor, ketoconazole (KTZ), on panobinostat exposure in patients (increased AUC 1.8-fold and $C_{\max }$ of 1.6-fold), suggesting that CYP3A4 contribution to total panobinostat CL is $\sim 40 \%$ (Hamberg et al., 2011).

The purpose of this article is to present the results identifying the P450 enzyme(s) involved in the oxidative metabolism of panobinostat in human liver and determination of their relative contributions in vitro and scaled contributions in vivo. In addition, we present the in vitro P459 drug-drug interaction (DDI) properties (inhibition and induction) of panobinostat. Based on these results, as well as the clinical results of the human radiolabeled ADME study (Clive et al., 2012) and clinical drug interactions with KTZ (Hamberg et al., 2011), a physiologically based pharmacokinetic (PBPK) model using the Simcyp Simulator (Certara Inc., Princeton, NJ) was constructed using panobinostat's physiochemical properties, absorption, distribution, and CL properties optimized from modeling clinical PK data. This PBPK model was then verified to predict the interaction of panobinostat with the weak CYP3A4 inducer DEX and then used to predict clinically untested scenarios: the effect of panobinostat with the strong CYP3A4 inducer, rifampin (RIF), as well as the drug interaction with the sensitive CYP3A4 substrate, midazolam (MDZ). In addition, an Advanced Compartmental Absorption and Transit (ACAT) PBPK model for panobinostat was built using GastroPlus to evaluate the effects of changing $\mathrm{pH}$ (e.g., as with coadministration of acid-reducing agents) on the absorption of panobinostat in humans. We describe here how these in vitro DDI studies and PBPK modeling results helped to define the FDA-approved language for the product label regarding drug interactions and dosing recommendations for panobinostat.

\section{Materials and Methods}

\section{Materials}

$\left[{ }^{14} \mathrm{C}\right]$ Panobinostat was synthesized in house (Novartis, East Hanover, NJ). The specific activity was $50-52 \mathrm{mCi} / \mathrm{mmol}$ with $>95 \%$ radiochemical purity. Pooled human liver microsomes (HLM) were purchased from XenoTech, LLC (Kansas
City, KS) and Corning Gentest (Tewksbury, MA). Cryopreserved hepatocytes were purchased from Bioreclamation IVT (Baltimore, MD) and Corning Gentest. Recombinant human P450 and UDP-glucuronosyltransferase (UGT) enzymes, hydroxybupropion, $6 \alpha$-hydroxypaclitaxel, $4{ }^{\prime}$-hydroxydiclofenac, $4^{\prime}$-hydroxy- $S$ mephenytoin, $N$-desethylamodiaquine, and $S$-mephenytoin were also purchased from Corning Gentest. The following chemicals were obtained from SigmaAldrich (St. Louis, MO): $6 \beta$-hydroxytestosterone, acetaminophen, alamethicin, ammonium acetate, amodiaquine, $\beta$-napthoflavone (BNF), bupropion, chlorzoxazone, diclofenac, dimethylsulfoxide, furafylline, gemfibrozil glucuronide, midazolam, $\mathrm{MgCl}_{2}$, MTT (3-[4,5-dimethylthiazol-2-yl]-2,5-diphenyl tetrazolium bromide), NADPH, paclitaxel, paroxetine, perchloric acid, phenacetin, phenobarbital (PB), potassium phosphate (mono- and di-basic), rifampicin (RIF), testosterone, ticlopidine, troleandomycin, and UDPGA. Bufuralol hydrochloride, 1'-hydroxybufuralol maleate, 6-hydroxychlorzoxazone, $S$-mephenytoin, $4{ }^{\prime}$-hydroxy-S-mephenytoin and $1^{\prime}$-hydroxy-midazolam were obtained from Ultrafine Chemicals (Manchester, UK). Tienilic acid was obtained internally at Novartis. Acetonitrile, formic acid, and methanol were purchased from Fisher Scientific Co. (Pittsburgh, PA). IN FLOW 2:1 was purchased from LabLogic Systems, Inc. (Brandon, FL).

\section{In Vitro P450 Inhibition}

The potential for reversible and/or time-dependent inhibition of CYP1A2, CYP2B6, CYP2C8, CYP2C9, CYP2C19, CYP2D6, CYP2E1, and CYP3A4/5 by panobinostat was investigated in vitro using pooled HLM (mixed gender, $n=50$; XenoTech, LLC or $n=150$; Corning Gentest). P450 activity was assessed using the probe reactions, phenacetin $O$-deethylation (CYP1A2), bupropion hydroxylation (CYP2B6), paclitaxel $6 \alpha$-hydroxylation or $N$-deethylamodiaquine (CYP2C8), diclofenac 4'-hydroxylation (CYP2C9), S-mephenytoin 4'-hydroxylation (CYP2C19), bufuralol 1'-hydroxylation (CYP2D6), chlorzoxazone 6-hydroxylation (CYP2E1), and midazolam-1'-hydroxylation, and testosterone $6 \beta$-hydroxylation (CYP3A4/5). For reversible inhibition, incubations $\left(37^{\circ} \mathrm{C}, 10-30\right.$ minutes) were composed of the following (final concentrations): potassium phosphate buffer (100 mM, pH 7.4), NADPH (1 mM), $\mathrm{MgCl}_{2}(5 \mathrm{mM})$, HLM protein $(0.05-0.5 \mathrm{mg}$ protein/ml), probe substrate $(5 \mu \mathrm{M}$ phenacetin, diclofenac, bufuralol, or MDZ, $10 \mu \mathrm{M}$ paclitaxel or chlorzoxazone, $15 \mu \mathrm{M}$ $S$-mephenytoin, or $25 \mu \mathrm{M}$ bupropion or testosterone), varying concentrations of panobinostat $(0-100 \mu \mathrm{M})$, and organic solvent $(<1.5 \%)$. The reactions were run in triplicate. After 3 minutes of thermal equilibration, the reactions were initiated by the addition of NADPH and terminated by the addition of acetonitrile (two volumes). Reactions were previously shown to be linear with respect to time and protein concentration (results not shown). Formation of probe substrate metabolites from the preceding samples, acetaminophen, hydroxybupropion, $6 \alpha$-hydroxypaclitaxel or $N$-deethylamodiaquine, $4^{\prime}$-hydroxydiclofenac, $4^{\prime}$-hydroxy- $S$ mephenytoin, 1'-hydroxybufuralol, 6-hydroxychlorzoxazone, 1'-hydroxymidazolam, or $6 \beta$-hydroxytestosterone, was determined by liquid chromatography-tandem mass spectrometry (LC-MS/MS) after concentration and reconstitution of the samples in acetonitrile/water containing an internal standard. $\mathrm{IC}_{50}$ values for the inhibition of P450 enzyme were determined by visual inspection of the data (percentage of control P450 activity vs. panobinostat concentration). Because of the low $\mathrm{IC}_{50}$ value associated with CYP2D6 inhibition, the corresponding apparent $K_{\mathrm{i}}$ value was determined for burfuralol 1'-hydroxylation activity. The incubations were carried out as described already with varying concentrations of bufuralol $(0.5-10 \mu \mathrm{M})$ and panobinostat $(0-0.2 \mu \mathrm{M})$. The $K_{\mathrm{i}}$ value was determined by nonlinear regression analysis using an equation for competitive inhibition: $v=V_{\max }[\mathrm{S}] /\left(K_{\mathrm{m}}\left(1+[\mathrm{I}] / K_{\mathrm{i}}\right)+[\mathrm{S}]\right)$, where $v$ is the initial velocity, $V_{\max }$ is the maximum velocity, $K_{\mathrm{m}}$ is the Michaelis-Menten constant, [S] is the substrate concentration, $[\mathrm{I}]$ is the inhibitor concentration, and $K_{\mathrm{i}}$ is the inhibition constant.

For assessments of time-dependent inhibition of CYP1A2, CYP2B6, CYP2C8, CYP2C9, CYP2C19, CYP2D6, or CYP3A4/5 activity, panobinostat $(0-50$ or $0-100 \mu \mathrm{M})$ was preincubated $\left(37^{\circ} \mathrm{C}\right)$ with HLM $(0.5$ or $1 \mathrm{mg}$ microsomal protein $/ \mathrm{ml}$ ) in the same buffer components as described herein (in duplicate). The preincubations were initiated by the addition of NADPH. After various preincubation times, aliquots were removed and transferred to an enzyme activity assay mixture (20-fold dilution of the preincubation reaction) containing the same buffer components as the preincubation and $\mathrm{P} 450$ probes substrates to determine remaining activity. The concentrations of probe substrates in the enzyme activity assay were $100 \mu \mathrm{M}$ phenacetin (CYP1A2), $1.5 \mathrm{mM}$ bupropion 
(CYP2B6), $20 \mu \mathrm{M}$ amodiaquine (CYP2C8), $50 \mu \mathrm{M}$ diclofenac (CYP2C9), $300 \mu \mathrm{M} \mathrm{S}$-mephenytoin (CYP2C19), $50 \mu \mathrm{M}$ bufuralol (CYP2D6), and $20 \mu \mathrm{M}$ $\mathrm{MDZ}(\mathrm{CYP} 3 \mathrm{~A} 4 / 5)$. The enzyme activity assay reactions were incubated at $37^{\circ} \mathrm{C}$ for 6-8 minutes, and the reaction was terminated as described. Positive-control time-dependent inhibitors included furafylline (CYP1A2), ticlopidine (CYP2B6 and CYP2C19), gemfibrozil glucuronide (CYP2C8), tienilic acid (CYP2C9), paroxetine (CYP2D6), and troleandomycin (CYP3A4/5). Preparation of the samples for analysis of the probe substrate metabolite formation by LC-MS/MS was as has been described. The inactivation parameters, $k_{\text {inact }}$ (maximum inactivation rate) and $K_{\mathrm{I}}$ (concentration at $1 / 2 k_{\text {inact }}$ ), were determined by plotting the natural log of the percentage of control activity remaining after incubations with increasing inhibitor concentration, plotted against the time of the preincubation. The absolute value of the observed rate of inactivation $\left(k_{\mathrm{obs}}\right)$ was then plotted against the inhibitor concentration, and the data were analyzed by nonlinear regression using the equation: $k_{\mathrm{obs}}=k_{\text {inact }}[\mathrm{I}] / \mathrm{K}_{\mathrm{I}}+[\mathrm{I}]$.

\section{In Vitro P450 Induction}

The potential for induction of CYP1A2, CYP2B6, CYP2C9, and CYP3A4 mRNA and enzyme activities by panobinostat was assessed in vitro using cryopreserved hepatocytes from three donors. The cells were treated with panobinostat $(0.01,0.1$, or $1 \mu \mathrm{M})$, the positive controls, RIF $(0.01,0.1,1$, or $10 \mu \mathrm{M}), \mathrm{PB}(1 \mathrm{mM})$, or BNF $(10 \mu \mathrm{M})$, and the vehicle control $(0.1 \%$ dimethylsulfoxide) for 72 hours. The medium was changed with the fresh addition of the compounds or vehicle control 24 hours after the first treatment dose. Induction of mRNA was determined by real-time polymerase chain reaction (PCR) using the comparative $\mathrm{C}_{\mathrm{T}}$ method, enzyme activity was measured in situ using P450-selective probe substrates, and cell viability was assessed using the MTT (3-[4,5-dimethylthiazol-2-yl]-2,5-diphenyl tetrazolium bromide; Sigma-Aldrich) assay after the treatment period. The method was as essentially described by Flarakos et al. (2016).

\section{In Vitro P450 Reaction Phenotyping}

In Vitro Metabolism. The metabolism of $\left[{ }^{14} \mathrm{C}\right]$ panobinostat was examined in pooled HLM (mixed gender, $n=46$, Corning Gentest) in the presence of NADPH and/or UDPGA. HLM (1 mg protein/ml) in $100 \mathrm{mM}$ potassium phosphate buffer $\left(\mathrm{pH}\right.$ 7.4) were preincubated with alamethicin $\left(60 \mu \mathrm{g}\right.$ alamethicin $\cdot \mathrm{mg} \operatorname{protein}^{-1}$, final concentration) for 15 minutes on ice. $\mathrm{MgCl}_{2}(5 \mathrm{mM}$, final concentration) and $\left[{ }^{14} \mathrm{C}\right]$ panobinostat (39 $\mu \mathrm{M}$, final concentration) were then added, and the samples were thermally equilibrated at $37^{\circ} \mathrm{C}$ for 3 minutes. The reactions (in singlet) were initiated with $4 \mathrm{mM}$ UDPGA and/or $1 \mathrm{mM} \mathrm{NADPH}$ (final concentrations), and the samples were incubated for 30 minutes at $37^{\circ} \mathrm{C}$. Control incubations did not contain cofactors. The reactions were terminated by the addition of 1:20 volume of cold $35 \%$ perchloric acid to avoid excessive dilution of the sample to improve radiochemical detection sensitivity. The precipitated protein was removed by centrifugation at 39,000 $\mathrm{g}$ for 10 minutes at $\sim 4^{\circ} \mathrm{C}$ in an Avante 30 high-speed microcentrifuge (Beckman Coulter, Fullerton, CA). Aliquots of the supernatants were analyzed by reverse-phase high-performance liquid chromatography (HPLC). The HPLC chromatographic equipment consisted of a Waters 2695 separation module equipped with an autosampler and quaternary pump system (Waters, Milford, MA). The chromatographic separation was performed on a Phenomenex Synergy Hydro RP column $(150 \times 4.6 \mathrm{~mm}, 4 \mu \mathrm{m})$ at a temperature of $30^{\circ} \mathrm{C}$ (Phenomenex, Torrance, CA). Gradient elution consisted of solvent A $(10 \mathrm{mM}$ ammonium acetate, $0.1 \%$ formic acid, $\mathrm{v} / \mathrm{v}, \mathrm{pH} 3.5$ ) and solvent $\mathrm{B}$ (acetonitrile/ methanol, $82 / 18, \mathrm{v} / \mathrm{v}$ ) at a flow rate of $1 \mathrm{ml} / \mathrm{min}$. The elution was as follows: $0 \%-$ $10 \%$ B (0-10 minutes), 10\%-18.5\% B (10-27 minutes), 18.5\%-29.5\% B (2745 minutes), $29.5 \%-100 \%$ B (45-52 minutes). Radioactivity was measured in line with a $\beta$-RAM radioactivity detector (Lablogic Systems Inc) with the addition of $3 \mathrm{ml}$ of liquid scintillant per minute (IN FLOW 2:1; Lablogic Systems Inc.) to the HPLC eluate. Chromatograms were evaluated using Winflow HPLC application software (version 1.4a; Lablogic Systems Inc.).

Enzyme Identification. To identify the P450 enzyme(s) involved in the metabolism of panobinostat in humans, $\left[{ }^{14} \mathrm{C}\right]$ panobinostat $(39 \mu \mathrm{M}$, final concentration) was incubated with the recombinant human (rh) P450 enzymes: CYP1A1, CYP1A2, CYP1B1, CYP2A6, CYP2B6, CYP2C8, CYP2C9, CYP2C18, CYP2C19, CYP2D6, CYP2E1, CYP2J2, CYP3A4, CYP3A5, CYP4A11 (100 pmol P450/ml) or control microsomes in $100 \mathrm{mM}$ potassium phosphate buffer ( $\mathrm{pH}$ 7.4) containing $5 \mathrm{mM} \mathrm{MgCl}$, final concentrations. The reactions (in singlet) were thermally equilibrated at $37^{\circ} \mathrm{C}$ and initiated by the addition of NADPH ( $1 \mathrm{mM}$, final concentration). The samples were incubated for 30 minutes at $37^{\circ} \mathrm{C}$ and were quenched, processed, and analyzed by HPLC with in-line radioactivity detection, as described.

Relative Contributions of $\mathbf{P 4 5 0}$ Enzymes. The relative contributions of CYP2C19, CYP2D6, and CYP3A4 enzymes to the in vitro hepatic oxidative CL of panobinostat were determined by rhP450 kinetics and scaling of the enzyme efficiencies to human liver microsomal CL. CYP2C19 (25 pmol P450/ml, $0.20 \mathrm{mg}$ microsomal protein $/ \mathrm{ml})$, CYP2D6 (25 pmol P450/ml, $0.24 \mathrm{mg}$ microsomal protein $/ \mathrm{ml}$ ), CYP3A4 (50 pmol $\mathrm{P} 450 / \mathrm{ml}, 0.26 \mathrm{mg}$ microsomal protein $/ \mathrm{ml}$ ) were preincubated with varying concentrations of $\left[{ }^{14} \mathrm{C}\right]$ panobinostat (in duplicate) in potassium phosphate buffer with $\mathrm{MgCl}_{2}$ for 3 minutes. The reactions were initiated with $\mathrm{NADPH}$ and incubated at $37^{\circ} \mathrm{C}$ for 5 minutes for rhCYP2D6 incubations and up to 10 and 20 minutes for rhCYP2C19 and rhCYP3A4 incubations, respectively. Control samples at each concentration of $\left[{ }^{14} \mathrm{C}\right]$ panobinostat were prepared using control microsomes at the same protein concentration. The samples were quenched, processed, and analyzed by HPLC as described already herein or with offline low- level radioactivity counting. For the low-level counting, the HPLC eluate was collected with a fraction collector (FC204; Gilson Inc., Middleton, WI) at 0.25 minute per fraction into Deepwell LumaPlate-96 plates (PerkinElmer Life and Analytical Sciences). The fractions were dried with a stream of nitrogen, and radioactivity was counted with a TopCount NXT Microplate Scintillation and Luminescence Counter (PerkinElmer Life and Analytical Sciences) with a counting time of 10 minutes/well. For calculation of metabolism activity in all kinetic studies, the amount of radioactivity present in impurity peaks identified in the control incubations that coeluted with actual metabolites were subtracted out from the identical peaks in the reaction incubations. To determine the metabolism activity of $\left[{ }^{14} \mathrm{C}\right]-$ panobinostat, the percentage of radioactivity of each peak in the HPLC chromatogram was quantified (totaling $100 \%$ ). The amount of specific metabolites formed in the reaction was based on the percentage of radioactivity in the product peak with respect to the total amount of $\left[{ }^{14} \mathrm{C}\right]$ panobinostat in the starting reaction. The metabolism activity was therefore calculated as the amount of product formed per total amount of $\mathrm{P} 450$ enzyme in the reaction per reaction time (i.e., nanomoles of metabolite formed/nanomoles of P450 enzyme/hour).

$\left[{ }^{14} \mathrm{C}\right]$ Panobinostat metabolism activity was plotted against substrate concentration and the kinetic parameters, and $K_{\mathrm{m}}$ and $V_{\max }$ values were determined by nonlinear regression analysis using the Michaelis Menten equation: $v=V_{\max }[\mathrm{S}] /$ $\left(K_{\mathrm{m}}+[\mathrm{S}]\right)$. Total $\left[{ }^{14} \mathrm{C}\right]$ panobinostat metabolism remained $\sim \leq 20 \%$ for all reactions. To estimate the relative contribution of CYP2C19, CYP2D6, and CYP3A4 to the metabolism of panobinostat in HLM (shown in Table 1), we determined a relative activity factor (RAF). The RAF is the ratio of a specific $\mathrm{P} 450$ activity in the recombinant expressed microsomes versus the same specific P450 activity in the pooled HLM under substrate saturating conditions. The relative activity factors for CYP2C19, CYP2D6, and CYP3A4 were determined by comparing probe substrate metabolism activities (determined by the vendor): $S$-mephenytoin $4^{\prime}$-hydroxylase activities in pooled HLM $(56 \mathrm{pmol} / \mathrm{mg}$ of protein per minute) and rhCYP2C19 (22 pmol/pmol P450 per minute or $2750 \mathrm{pmol} / \mathrm{mg}$ of protein per minute), bufuralol 1'-hydroxylase activities in HLM (94 pmol/mg of protein per minute), rhCYP2D6 (47 pmol/pmol P450 per minute or $4841 \mathrm{pmol} / \mathrm{mg}$ of protein per minute), and testosterone $6 \beta$-hydroxylase activities (CYP3A4/5) in HLM ( $4300 \mathrm{pmol} / \mathrm{mg}$ of protein per minute), and rhCYP3A4 (180 pmol/pmol P450 per minute or $35,280 \mathrm{pmol} / \mathrm{mg}$ of protein per minute). The relative activity factors were determined to be 49.1 for rhCYP2C19 [as rhCYP2C19 was 49.1 -fold more active (per milligram of microsomal protein) than the CYP2C19 activity in HLM], 51.5 for rhCYP2D6, and 8.20 for rhCYP3A4.

\section{Panobinostat Simcyp PBPK Model}

Input Parameters. The platform used for the PBPK modeling was the Simcyp simulator (version 13, release 1 or 2). Physicochemical and pharmacokinetic parameters of panobinostat used for the PBPK model are summarized in Table 2. The fraction of dose absorbed from the gastrointestinal tract $\left(f_{\mathrm{a}}\right)$ was estimated to be 1 as unchanged panobinostat in the feces of humans accounted for $\leq 3.3 \%$ of the administered dose, suggesting nearly complete oral absorption (Clive et al., 2012). The absorption rate constant $\left(k_{\mathrm{a}}\right)$ was estimated to be $0.32 /$ hour from a population PK analysis (Savelieva et al., 2015; Supplemental Table 2b). The $f u_{\text {gut }}$ term was entered as 1 (default). The $f u_{\text {gut }}$ value was set to 1 to minimize the panobinostat $F_{\mathrm{g}}$ value and to be conservative with respect to CYP3A4-mediated 
TABLE 1

Kinetic parameters for panobinostat metabolism by recombinant human CYP2C19, CYP2D6, and CYP3A4

$\mathrm{K}_{\mathrm{m}, \mathrm{u}}$, unbound $\mathrm{K}_{\mathrm{m}}$ (corrected for the unbound fraction in the microsomes, fu $\mathrm{mic}_{\text {) }}$ ) The fu $\mathrm{m}_{\mathrm{mic}}$ was 1.0 for the rhCYP2C19 and rhCYP2D6 incubations $(0.20$ and $0.24 \mathrm{mg}$ of protein/ml, respectively) and 0.99 for the rhCYP3A4 incubations $(0.26 \mathrm{mg}$ protein/ml), determined by ultracentrifugation (data not shown).

\begin{tabular}{|c|c|c|c|c|c|c|c|}
\hline \multirow{2}{*}{ P450 } & \multirow{2}{*}{ Metabolite } & \multirow{2}{*}{$K_{\mathrm{m}, \mathrm{u}} \mu \mathrm{M}$} & \multirow{2}{*}{$V_{\max } \mathrm{h}^{-1}$} & \multirow{2}{*}{$\begin{array}{c}\text { Enzyme Efficiency } \\
V_{\max } / K_{\mathrm{m}, \mathrm{u}} \mathrm{ml} / \mathrm{h} \\
\text { per } \mathrm{nmol} \mathrm{P} 450\end{array}$} & \multicolumn{3}{|c|}{$\begin{array}{l}\text { Estimation of Individual P450 Contributions } \\
\text { to Total HLM Oxidative } \mathrm{CL}_{\text {int }} \text { of Panobinostat }\end{array}$} \\
\hline & & & & & $\begin{array}{l}\text { Scaled } V_{\max } \mathrm{nmol} / \mathrm{h} \\
\text { per mg of Protein }\end{array}$ & $\begin{array}{l}\text { Scaled } \mathrm{CL}_{\text {int,u }} \mathrm{ml} / \mathrm{h} \\
\text { per mg Protein }\end{array}$ & $\%$ Contribution $^{\mathrm{b}}$ \\
\hline \multirow[t]{3}{*}{ CYP2C19 } & Total $^{c}$ & $6.41 \pm 0.40$ & $118 \pm 1.7(14.7)^{d}$ & 18.4 & 0.299 & 0.0466 & 6 \\
\hline & M9 & $10.8 \pm 2.0$ & $6.35 \pm 0.46(0.792)$ & 0.588 & 0.0161 & 0.00149 & \\
\hline & $\mathrm{M} 24.2+\mathrm{M} 24.2 \mathrm{~A}$ & $7.93 \pm 0.43$ & $120 \pm 1.7(15.1)$ & 15.1 & 0.308 & 0.0388 & \\
\hline \multirow[t]{4}{*}{ CYP2D6 } & Total & $0.554 \pm 0.043$ & $48.3 \pm 0.74(4.97)$ & 87.2 & 0.0965 & 0.174 & 21 \\
\hline & M9 & $10.3 \pm 5.0$ & $2.72 \pm 0.56(0.281)$ & 0.264 & 0.00546 & 0.000530 & \\
\hline & $\mathrm{M} 24.2+\mathrm{M} 24.2 \mathrm{~A}$ & $0.536 \pm 0.048$ & $40.2 \pm 0.71(4.14)$ & 75.0 & 0.0804 & 0.150 & \\
\hline & M43.5 & $0.424 \pm 0.042$ & $6.41 \pm 0.12(0.661)$ & 15.1 & 0.0128 & 0.0303 & \\
\hline \multirow[t]{4}{*}{ CYP3A4 } & Total & $8.98 \pm 0.44$ & $226 \pm 2.7(44.4)$ & 25.1 & 5.41 & 0.603 & 73 \\
\hline & M9 & $14.2 \pm 0.99$ & $56.8 \pm 1.1(11.1)$ & 4.00 & 1.35 & 0.0953 & \\
\hline & M24.2 & $7.49 \pm 0.58$ & $160 \pm 2.8(31.4)$ & 21.3 & 3.83 & 0.512 & \\
\hline & M43.5 & $21.0 \pm 1.9$ & $11.6 \pm 0.35(2.28)$ & 0.552 & 0.278 & 0.0132 & \\
\hline
\end{tabular}

${ }^{a}$ Scaled $V_{\max }$ is an estimate of the $\mathrm{V}_{\max }$ for that P450 enzyme in HLM. It was calculated by dividing the $V_{\max }$ value in parentheses (units of nanomoles per hour per milligram of microsomal protein) from the rhP450 enzyme by the RAF values: 49.1 (CYP2C19), 51.5 (CYP2D6), 8.20 (CYP3A4), see Materials and Methods section.

${ }^{b}$ The $\%$ contribution of the individual P450 enzyme to total panobinostat oxidative $\mathrm{CL}_{\text {int,u }}$ in $\mathrm{HLM}=$ individual $\mathrm{P} 450 \mathrm{CL}_{\text {int,u }} / \Sigma \mathrm{P} 450 \mathrm{CL}_{\text {int,u }} \times 100$

${ }^{c}$ Total metabolism.

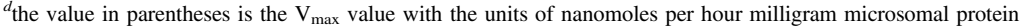

DDI in the intestine (i.e., not to underpredict the DDI). Intestinal metabolism was estimated by "top-down" modeling of the interaction of panobinostat with the CYP3A4 inhibitor KTZ, as well as modeling the proper PK of panobinostat (e.g., $C_{\max }$, AUC, concentration-time profiles) from the clinical trials used for model development (Table 3). Parameter sensitivity analysis of the panobinostat $f u_{\text {gut }}$ value and the predicted $F_{\mathrm{g}}$ and DDI magnitude of panobinostat in the presence of KTZ are shown in Supplemental Fig. 1 . The $Q_{\text {gut }}$ term (described in RostamiHodjegan and Tucker, 2002)), which also impacts $F_{\mathrm{g}}$, was set to be 2.8 liters/h to optimize the predicted clinical PK of panobinostat and the magnitude of drug interaction with KTZ. Parameter sensitivity analysis of the impact of the $\mathrm{Q}_{\text {gut }}$ value on panobinostat $F_{\mathrm{g}}$ and the predicted DDI magnitude of panobinostat with KTZ coadministration is shown in Supplemental Fig. 2. The minimal PBPK model within the Simcyp framework was used with a single adjusting compartment. The $k_{\text {in }}$ and $k_{\text {out }}$ values were estimated to be 1.42 and 0.04 per hour of analysis (Savelieva et al., 2015; Supplemental Table 2b, as $k_{24}$ and $k_{42}$ ). The volume of the compartment $\left(V_{\mathrm{sac}}\right)$ was entered as $10.5 \mathrm{liters} / \mathrm{kg}$. This value was manually optimized to predict the clinical PK of panobinostat of the trials used for model qualification. The volume of distribution $\left(V_{\mathrm{ss}}\right)$ was estimated to be $\sim 13$ 1/kg. Panobinostat hepatic microsomal intrinsic clearance $\left(\mathrm{CL}_{\text {int }}\right)$ was backcalculated from the clinically observed median plasma CL of 33 liters/hour (Savelieva et al., 2015) using the enzyme kinetics retrograde model implemented in Simcyp. Based on an observed 1.78-fold increase in panobinostat exposure after KTZ administration in patients (Hamberg et al., 2011), the predicted fraction metabolized $(f m)$ by CYP3A4 $\left(f m_{\text {CYP3A4 }}\right)$ was estimated as $\sim 0.4\left(\mathrm{AUC}_{\mathrm{i}} / \mathrm{AUC}=\right.$ 1/1- $\left.f m_{\text {CYP3A4 }}\right]$ ) (Shou et al., 2008). This relationship assumes complete inhibition of the CYP3A-mediated CL of panobinostat by KTZ. This value was also in line with results from the human ADME study in which P450-mediated oxidative CL was estimated to range from a maximum of $30 \%$ to $47 \%$ of the dose (Clive et al., 2012). The $f m_{\mathrm{CYP}}$ values for the CYP2D6 and CYP2C19 enzymes were estimated relative to CYP3A4 based on the HLM scaled recombinant enzyme $\mathrm{CL}_{\text {int,u }}$ values for total metabolism (Table 1). If CYP3A4 represented $40 \%$ of the total CL of panobinostat in humans, then CYP2D6 and CYP2C19 were estimated to approximately contribute $12 \%$ and $3 \%$ of the total CL, respectively. This was based on the estimations of CYP2D6 and CYP2C19 $\mathrm{CL}_{\text {int,u }}$ in HLM being 3.4and $\sim 12$-fold less than the CYP3A4 $\mathrm{CL}_{\text {int,u }}$ value (Table 1). The in vivo $\mathrm{fm}_{\mathrm{CYP}}$ values of CYP3A4, CYP2D6, and CYP2C19 were therefore entered as $0.4,0.12$, and 0.03 , respectively. The resultant entries in the model for the individual P450 $\mathrm{CL}_{\text {int }}$ values and additional HLM CL calculated in Simcyp are as shown in Table 2. Panobinostat mean renal CL was entered as 3.57 liters/hour (Clive et al., 2012). The actual model output values of the $\mathrm{fm}$ or $\mathrm{fe}$ (fraction of elimination) for panobinostat in Simcyp were 39\%, 10\%, 3\%, 34\%, and 14\% for CYP3A4, CYP2D6, CYP2C19, additional HLM-mediated CL (representing non-P450mediated metabolic clearance) and renal elimination, respectively. The following were the resultant PBPK predicted values (mean, range): plasma CL (30 liters/ hour, 16-57), $F(0.46,0.21-0.71), f_{\mathrm{a}}(0.88,0.39-1.0), F_{\mathrm{g}}(0.68,0.41-0.93)$, and $F_{\mathrm{h}}(0.77,0.59-0.90)$.

Model Development and Application. The Simcyp simulator was used for these simulations with the Simcyp "healthy volunteer" population. The proportion of females in the model was set as 0.5 . Ten trials of 10 subjects were simulated for each dosing regimen. The input parameters for panobinostat are described in Table 2. Input values for MDZ, RIF, and KTZ (400 mg daily) were provided within the Simcyp simulator. The input values for these compounds can be found in the supplemental material (Supplemental Tables 1-3). The compound file for DEX was built "top-down," and the input parameters can be found in Supplemental Table 4. The DEX PBPK model was built to predict the PK of a single and multiple 20-mg doses of DEX (Supplemental Fig. 3, Supplemental Fig. 4, and Supplemental Table 5,) and the clinical DDI with the CYP3A4/5 probe substrate triazolam (i.e., weak CYP3A4 induction by DEX, Supplemental Table 6). The clinical trials used to develop the model for panobinostat can be found in Table 3. The model was developed to predict the PK parameters of a dose range of $10-80 \mathrm{mg}$ single and multiple Monday, Wednesday, Friday doses, as well as the DDI with the CYP3A4 inhibitor KTZ. The model was then verified to predict the weak interaction of panobinostat with DEX (San-Miguel et al., 2013; $\mathrm{Mu}$ et al., 2016) and applied to predict the DDI of panobinostat with the CYP3A4 inducer, RIF and the sensitive CYP3A4/5 substrate MDZ.

Parameter Sensitivity Analysis. Sensitivity analyses were performed both separately and together for the panobinostat CYP3A4 inactivation parameters $k_{\text {inact }}$ and $K_{\mathrm{I}}$ in prediction of the MDZ AUC ratio. The range of values used in the analysis was based on the standard deviation of the experimentally determined $k_{\text {inact }}$ and $K_{\mathrm{I}}$ values, vide infra. The range of $k_{\text {inact }}$ and $K_{\mathrm{I}}$ values examined in this analysis was, therefore, $1.18-1.55$ hours $^{-1}$ and $7.5-16.5 \mu \mathrm{M}$, respectively. Additional sensitivity analyses were performed separately for the panobinostat absorption rate constant $\left(k_{\mathrm{a}}\right)$, hepatic CYP3A4 enzyme degradation rate constant $\left(k_{\mathrm{deg}}\right)$, and inhibition constant $\left(K_{\mathrm{i}}\right)$ in the prediction of MDZ AUC ratio. The values used in the analysis covered an arbitrary 10 -fold range of the value derived from population PK analysis $\left(k_{\mathrm{a}} 0.32\right.$ hour $\left.^{-1}\right)$, literature (Obach et al., 2007, CYP3A4 $k_{\text {deg }} 0.0193$ hour $\left.^{-1}\right)$, and in vitro experimentation $\left(K_{\mathrm{i}} 7.5 \mu \mathrm{M}\right)$. Therefore, the ranges for $k_{\mathrm{a}}, k_{\mathrm{deg}}$, and $K_{\mathrm{i}}$ were $0.032-3.2$ hours $^{-1}, 0.00193-$ 0.193 per $\mathrm{h}$, and $0.75-75 \mu \mathrm{M}$, respectively.

Data Analysis. For single- and multiple-dose PK parameters, the $C_{\max }$ and $\mathrm{AUC}_{0-48}$ values are presented as the arithmetic mean with percent coefficient of variation $(\mathrm{CV} \%)$. The $T_{\max }$ is reported as the median and range. For the DDI studies, the PK parameters are reported as geometric means and $\mathrm{CV} \%$. The DDI is reported as the geometric mean $\mathrm{AUC}$ ratio $\left(\mathrm{AUC}_{\text {inhibited }}\right.$ or induced $\left./ \mathrm{AUC}_{\text {control }}\right)$ or geometric mean $C_{\max }$ ratio $\left(C_{\text {max,inhibited or induced }} / C_{\max , \text { control }}\right)$ with $90 \%$ confidence intervals $(\mathrm{CI})$, when the observed value was available. As a measure 
TABLE 2

Simcyp model input parameters for panobinostat

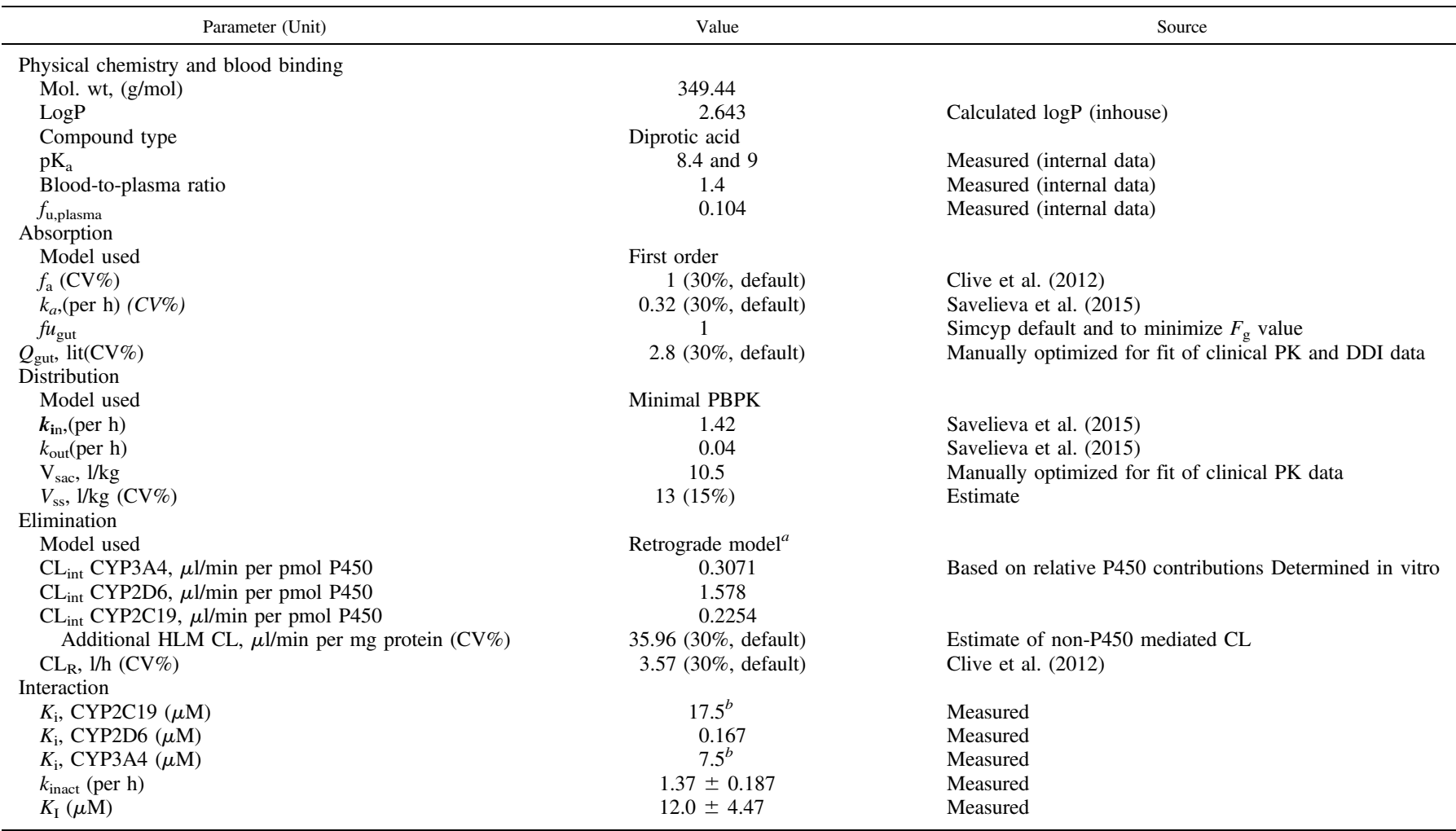

$\mathrm{B} / \mathrm{P}$, blood-to-plasma ratio.

${ }^{a}$ The P450 CL $\mathrm{C}_{\text {int }}$ and additional HLM CL was estimated using the Simcyp retrograde model, see Materials and Methods.

${ }^{b} \mathrm{IC}_{50} / 2$.

of model predictability, the percent prediction error $(\mathrm{PE})$ was calculated as shown in eq. 1. A prediction error of greater than $-50 \%$ and less than $+100 \%$ (predicted value within 2-fold of the observed value) for PK parameters is generally acceptable for PBPK model qualification (Sager et al., 2015). For DDI ratios, tighter criteria, particularly for DDI ratios between 0.5 and 2 , were followed (Guest et al., 2011):

Prediction error $(P E)=\left(\frac{\text { predicted value }- \text { observed value }}{\text { observed value }}\right) \times 100$

\section{Panobinostat GastroPlus ACAT Model}

Input Parameters. A human ACAT absorption model for panobinostat was built within GastroPlus (version 8.5; Simulations Plus, Inc., Lancaster, CA). The input parameters for the model are shown in Table 4. Panobinostat human PK parameters in the ACAT model were estimated from a population PK analysis using a three-compartment model (Savelieva et al., 2015). The median body weight in the data set used for the population PK analysis was $76.4 \mathrm{~kg}$. Body weight-normalized CL and $V_{\mathrm{c}}$, and the values for $k_{12}, k_{21}, k_{13}$, and $k_{31}$ were entered in the ACAT model as described in Supplemental Table $2 b$ of Savelieva

TABLE 3

Simulated trials

\begin{tabular}{|c|c|c|}
\hline Type of Simulation & Trial Description & Reference \\
\hline \multicolumn{3}{|l|}{ Model development } \\
\hline & $\begin{array}{l}\text { Study CLBH589B2101: A phase IA, two-arm, multicenter, dose-escalation } \\
\text { study of panobinostat administered orally on two dose schedules in adult } \\
\text { patients with advanced solid tumors or non-Hodgkin's lymphoma }\end{array}$ & $\begin{array}{l}\text { (http://www.accessdata.fda.gov/drugsatfda_docs/nda/ } \\
\text { 2015/205353Orig1s000ClinPharmR.pdf) }\end{array}$ \\
\hline & $\begin{array}{l}\text { Study CLBH589B2102: Phase IA/II, two-arm, open-label, dose-escalation study } \\
\text { of oral panobinostat administered via two dosing schedules with advanced } \\
\text { hematologic malignancies }\end{array}$ & $\begin{array}{l}\text { DeAngelo et al. 2013, (http://www.accessdata.fda.gov/ } \\
\text { drugsatfda_docs/nda/2015/ } \\
\text { 205353Orig1s000ClinPharmR.pdf) }\end{array}$ \\
\hline & $\begin{array}{l}\text { Study CLBH589B2110: Effect of KTZ-mediated CYP3A4 inhibition on clinical } \\
\text { PK of panobinostat in patients }\end{array}$ & $\begin{array}{l}\text { Hamberg et al. (2011), (http://www.accessdata.fda.gov/ } \\
\text { drugsatfda_docs/nda/2015/ } \\
\text { 205353Orig1s000ClinPharmR.pdf) }\end{array}$ \\
\hline Model verification & $\begin{array}{l}\text { Study CLBH589B2207: Phase Ib study of panobinostat and bortezomib in } \\
\text { relapsed or relapsed and refractory multiple myeloma (exposure of } \\
\text { panobinostat in combination with DEX) }\end{array}$ & San-Miguel et al. (2013), Mu et al. (2016) \\
\hline \multicolumn{3}{|c|}{ 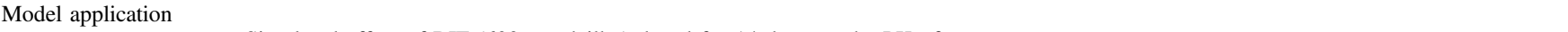 } \\
\hline & $\begin{array}{l}\text { Simulated effect of RIF (600 mg dallky) dosed for } 14 \text { days on the PK of } \\
\text { panobinostat ( } 20 \mathrm{mg} \text { single dose) on day } 7\end{array}$ & \\
\hline & $\begin{array}{l}\text { Simulated effect of panobinostat ( } 20 \mathrm{mg} \text { ) dosed orally on Monday, Wednesday, } \\
\text { Friday for } 2 \text { wk on the PK of MDZ (5-mg single dose) on day } 15\end{array}$ & \\
\hline
\end{tabular}


TABLE 4

GastroPlus ACAT model input parameters for panobinostat

\begin{tabular}{|c|c|}
\hline Parameter (unit) & Value \\
\hline Dosage form & Immediate release tablet $^{a}$ \\
\hline $\log \mathrm{P}^{b}$ & 2.8 \\
\hline Solubility (mg/ml) & 0.064 at $\mathrm{pH} 7.6$ \\
\hline $\mathrm{PKa}$ & 8.4 \\
\hline Dose volume $(\mathrm{ml})$ & 250 \\
\hline Particle density $(\mathrm{g} / \mathrm{ml})^{b}$ & 1.2 \\
\hline Mean particle radius $(\mu \mathrm{m})\left(\right.$ S.D. $\left.^{b}\right)$ & $15(0)$ \\
\hline Particle radius bin & 1 \\
\hline Precipitation time $(\mathrm{s})^{b}$ & 900 \\
\hline Diffusion coefficient $\left(\mathrm{cm}^{2} / \mathrm{s} \times 10^{5}\right)^{b}$ & 0.43 \\
\hline Permeability $\left(\mathrm{cm} / \mathrm{s} \times 10^{4}\right)$ & 2.289 \\
\hline Simulation time $(\mathrm{h})$ & 48 \\
\hline Body weight $(\mathrm{kg})$ & $69.1(20) 67.8$ (30) 79.1 (40 mg) \\
\hline First-pass elimination in small intestine (\%) & 60 \\
\hline First-pass elimination in liver, $\%$ & 26.1 \\
\hline $\mathrm{CL}(\text { liters } / \mathrm{h} / \mathrm{kg})^{c}$ & 0.433 \\
\hline$V_{\mathrm{c}}(\text { liters } / \mathrm{kg})^{c}$ & 0.325 \\
\hline $\mathrm{k}_{12}(\text { per h })^{c}$ & 1.81 \\
\hline $\mathrm{k}_{21}(\text { per } \mathrm{h})^{c}$ & 0.507 \\
\hline$k_{13}(\text { per h })^{c}$ & 1.42 \\
\hline$k_{31}(\text { per h })^{c}$ & 0.04 \\
\hline
\end{tabular}

${ }^{a}$ Dosage forms selected in GastroPlus for simulations.

${ }^{b}$ Predicted by ADMET predictor or default values in GastroPlus.

${ }^{c}$ Population PK analysis of human intravenous data.

et al. (2015). The solubility at $\mathrm{pH} 7.6$ at $37^{\circ} \mathrm{C}$ was entered as $0.064 \mathrm{mg} / \mathrm{ml}$. The first-pass elimination in the small intestine had to be defined to fit the ACAT model to the observed PK data. To accomplish this, an "optimization" module was used, and the first-pass elimination value in small intestine was selected for optimization. Akaike information criterion (AIC) was used to select the best fitted first-pass elimination value, and weighting was equal to 1 iters $/ y^{2}$. Optimized firstpass elimination value in small intestine was $60 \%$. The GastroPlus predicted firstpass elimination in the liver was $26.1 \%$. Other parameters needed for the model were as described previously (molecular weight, $\mathrm{pKa}, \mathrm{fu}_{\mathrm{p}}$, blood-to-plasma ratio) and presented in Table 4.

Model Application. The model was applied to predict the absorption of panobinostat with a range of stomach $\mathrm{pH}$ values of $0.5-8.0$.

\section{Results}

\section{In Vitro P450 Inhibition}

The potential for panobinostat to inhibit select $\mathrm{P} 450$ enzyme activities in a reversible and/or time-dependent fashion was investigated in vitro using pooled HLM. Panobinostat showed little to no reversible inhibition of CYP1A2, CYP2B6, CYP2C8, CYP2C9, and CYP2E1 activities and weak inhibition of CYP2C19 $\left(\mathrm{IC}_{50}\right.$ value of $\left.\sim 35 \mu \mathrm{M}\right)$ and CYP3A4/5 $\left(\mathrm{IC}_{50}\right.$ values of $\sim 7.5 \mu \mathrm{M}$ using $\mathrm{MDZ}$ as substrate and $\sim 15 \mu \mathrm{M}$ for testosterone). CYP2D6 was inhibited by panobinostat with an $\mathrm{IC}_{50}$ value of $\sim 2 \mu \mathrm{M}$ and $K_{\mathrm{i}}$ value of $0.167 \pm 0.0286 \mu \mathrm{M}$ (competitive inhibition). Results from preincubation experiments indicated that panobinostat was a time-dependent inhibitor of CYP3A4/5 and the inhibition was panobinostat concentration-dependent. The parameters associated with CYP3A4/5 time-dependent inhibition by panobinostat were $\left(\mathrm{K}_{\mathrm{I}}\right.$ and $\left.k_{\text {inact }}\right): 12.0 \pm 4.47 \mu \mathrm{M}$ and $1.37 \pm 0.187$ hour $^{-1}$.

\section{In Vitro P450 Induction}

Panobinostat was investigated for in vitro CYP enzyme induction potential in primary human hepatocytes of three donors. Panobinostat concentrations used in the induction study ranged from 0.01 to $1 \mu \mathrm{M}$ (3.49-349 $\mathrm{ng} / \mathrm{ml})$. These concentrations spanned $\sim 10$-fold above and below the $\mathrm{C}_{\text {max,ss }}$ concentration of the marketed $20 \mathrm{mg}$ oral dose ( $\sim 22 \mathrm{ng} / \mathrm{ml}$ ). The positive controls used in the study included RIF (up to
$10 \mu \mathrm{M}), \mathrm{PB}(1 \mathrm{mM})$, and $\mathrm{BNF}(10 \mu \mathrm{M})$ and the cells were treated every 24 hour for 72 hour. The cells were found to be viable after the induction period for the positive control inducers and panobinostat concentrations up to $0.1 \mu \mathrm{M}$, with a drop in cell viability of the three hepatocyte lots to $\sim 60 \%$ compared with the vehicle control at the $1 \mu \mathrm{M}$ concentration (data not shown). The mRNA levels of CYP1A2, CYP2B6, CYP2C9, and CYP3A4 in human hepatocytes after treatment with panobinostat with respect to the vehicle control were all $<$ twofold. Induction of CYP1A2, CYP2B6, CYP2C9, activity above twofold was only observed in one lot of hepatocytes (up to 2.2-, 2.6-, 2.4-fold, respectively). These induction levels were, however, less than $25 \%$ of the positive control inducers for CYP1A2 (BNF, 39-fold), CYP2B6 (PB, 12-fold), and CYP2C9 (PB, 11-fold) in that donor (Supplemental Table 7).

\section{In Vitro P450 Reaction Phenotyping}

Panobinostat was found to be metabolized in HLM in the presence of co-factors for CYP (NADPH) and UGT (UDPGA) enzymes to form five metabolites: M24.2 (cyclization/hydroxylation), M34.4 (glucuronide), M37.8 (hydroxamic acid reduction), M43.5 (hydrolysis to the carboxylic acid), and M9 (an uncharacterized product), Fig. 2. The identified metabolites were also found in human plasma and structures previously
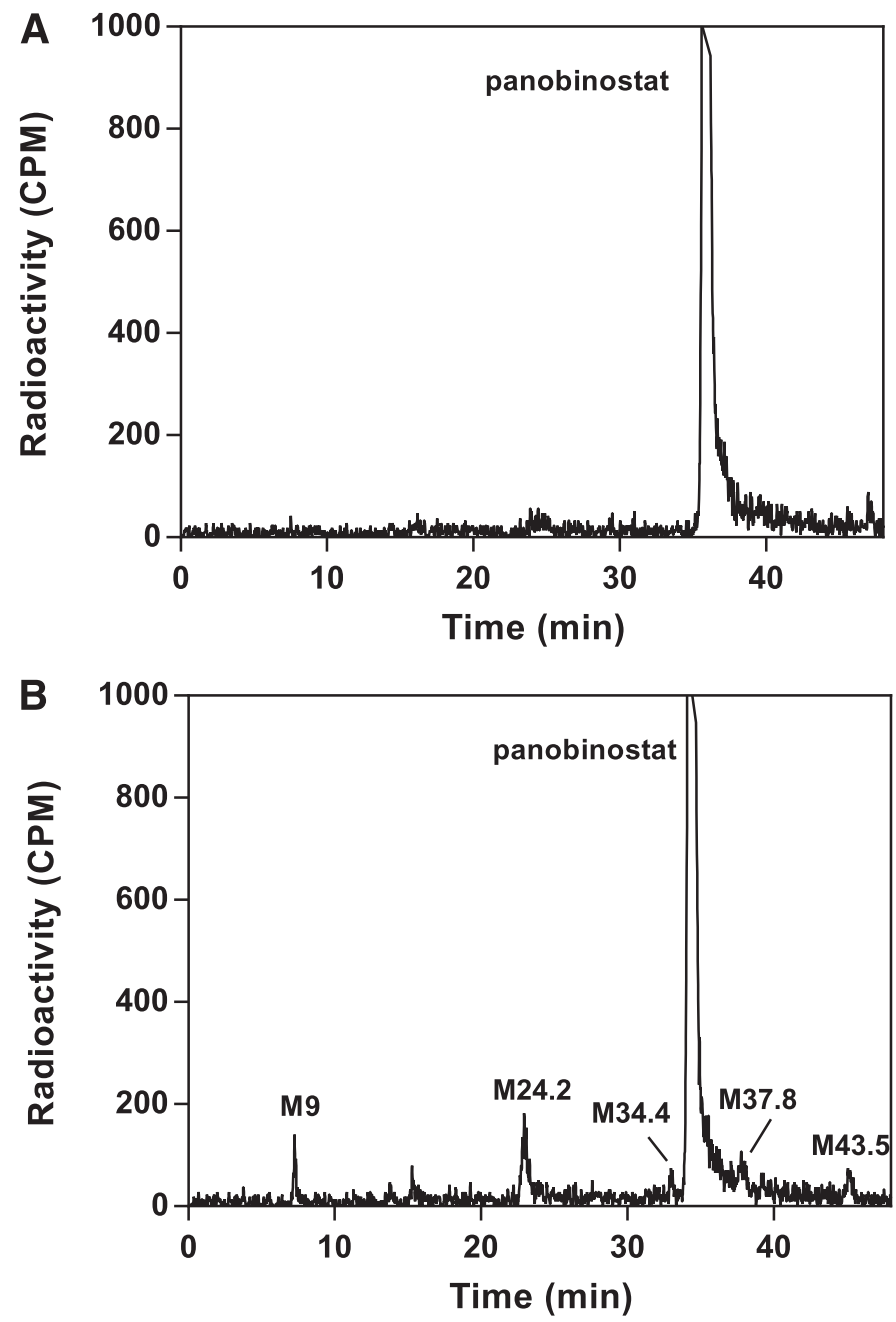

Fig. 2. Metabolism of panobinostat in HLM. (A) HPLC chromatographic profiles of $\left[{ }^{14} \mathrm{C}\right]$ panobinostat incubated with HLM in the absence (A) or presence (B) of the cofactors for P450- and UGT-enzyme mediated metabolism, NADPH, and UDPGA, respectively. 
characterized (Clive et al., 2012). Due to the low formation of the glucuronide M34.4 in HLM, the UGT enzymes involved in formation of this product were investigated by LC-MS analysis of individual rhUGT incubations with panobinostat. Human UGT1A1, UGT1A3, UGT1A8, and UGT1A9 were found to form this metabolite with trace levels detectable in incubations with UGT1A7 and UGT2B4 (data not shown). No further kinetic evaluations were performed for this metabolite. P450 enzymes involved in formation of the other metabolites identified in HLM were investigated by incubations with individual rhP450 enzymes. Panobinostat metabolites were found in incubations with rhCYP3A4, rhCYP2D6, and rhCYP2C19. No metabolism of panobinostat was observed by radiochemical detection in incubations with any other rhP450 enzyme, including rhCYP3A5. Kinetic analysis of metabolite formation was determined in incubations with the three individual rhP450 enzymes. Representative HPLC chromatograms of the metabolites formed in the rhP450 kinetic study and the graphs of the data can be found Fig. 3A (rhCYP2C19), Fig. 3B (rhCYP2D6), and Fig. 3C (rhCYP3A4). The kinetic parameters associated with formation of individual metabolites in the rhP450 incubations can be found in Table 1 and the nonlinear regression plots of the data can be found in Fig. 3D-F. The predominate metabolite formed in HLM, M24.2, was formed by all three rhP450 enzymes. A di-oxygenated metabolite, not found previously in HLM, M24.2A, co-eluted with M24.2 in incubations with CYP2C19 and CYP2D6. The hydrolysis product, M43.5, was found in incubations with CYP2D6 and CYP3A4. The enzyme efficiency for formation of this metabolite by CYP2D6 was $\sim 30$-times higher than CYP3A4 (15.1 ml/h per nanomole vs. $0.552 \mathrm{ml} / \mathrm{h}$ per nanomole if $\mathrm{P} 450)$ but compared with the other metabolites formed by these enzymes and scaled contributions to total HLM CL $\mathrm{H}_{\text {int }}$ was small (Table 1). It is likely, however, that the hydrolytic activity in plasma may also contribute to formation of M43.5 in humans in vivo, like that of other hydroxamic acids (Flipo et al., 2009). The hydroxamic acid reduction metabolite, M37.8, is not P450-mediated and was found to be formed in human hepatocytes and liver slices to a more substantial level (data not shown). The relatively low levels of this metabolite in HLM (yet higher abundance in whole-cell systems) indicate that the reductase may reside in the cytoplasm or organelles outside of the endoplasmic reticulum.

The relative contribution of the individual P450 enzymes to the total hepatic oxidative CL of panobinostat was determined by the RAF approach. The kinetically determined $V_{\max }$ value (units of picomoles per milligram of protein per minute) of the rhP450 enzymes was scaled to HLM $V_{\max }$ by the RAF factor (ratio of the activity of substrate probe drug metabolism at substrate saturating conditions in the rhP450 vs. HLM). The scaled HLM $V_{\max }$ value and calculated $\mathrm{CL}_{\text {int,u }}$ can be found in Table 1. The percent contribution of each of the P450 enzymes to total oxidative hepatic microsomal $\mathrm{CL}_{\text {int, }}$ by the three $\mathrm{P} 450$ enzymes (CYP2C19, CYP2D6, and CYP3A4) was estimated to be $6 \%, 21 \%$, and $73 \%$, respectively, in HLM. The relative contribution of the individual P450 enzymes to total oxidative $\mathrm{CL}_{\text {int }}$ in HLM determined by the RAF approach was similar to that calculated based on P450 enzyme abundance in HLM (see Supplemental Table 8).

\section{Panobinostat Simcyp PBPK Modeling}

Simulations of Panobinostat Single and Multiple Doses. In vitro phenotyping studies with panobinostat found CYP3A4 to be primarily responsible for the oxidative metabolism of panobinostat in HLM vide supra. In the human ADME study, based on metabolites identified in the urine and feces, P450-mediated oxidative CL was estimated to range from a maximum of $30 \%-47 \%$ of the dose (Clive et al., 2012). Consistent with this, the contribution of CYP3A4 to the total CL of panobinostat in humans was estimated from the clinical DDI study with KTZ to be $40 \%$ (Hamberg et al., 2011). Therefore, the PBPK model was
A
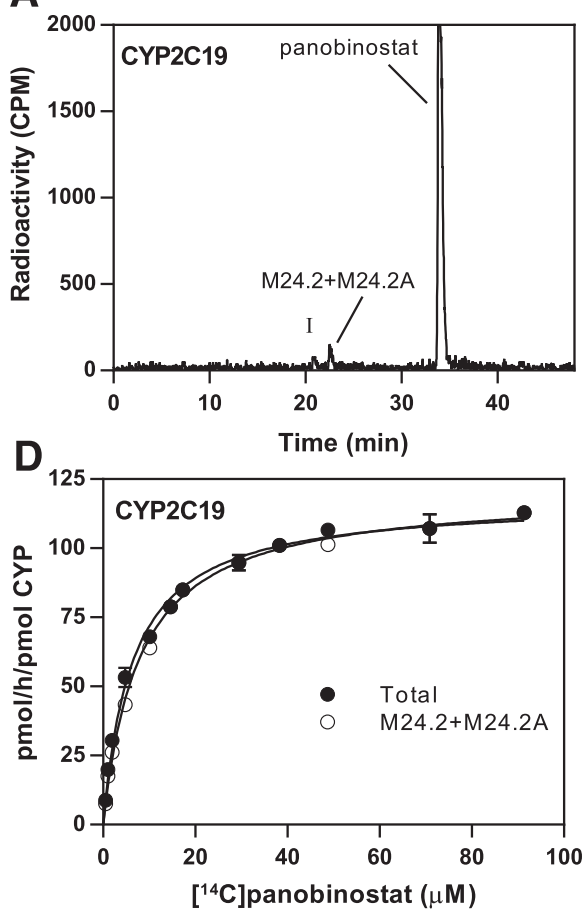

B

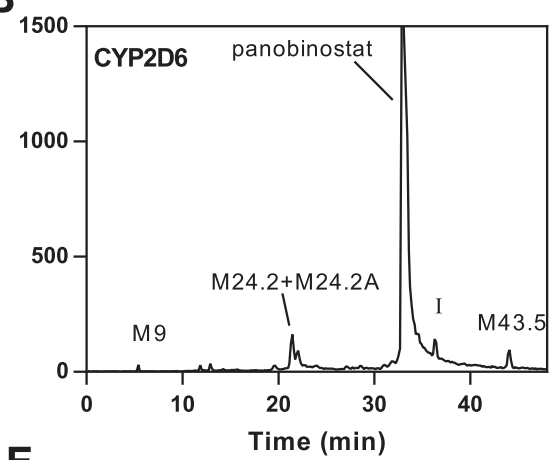

E

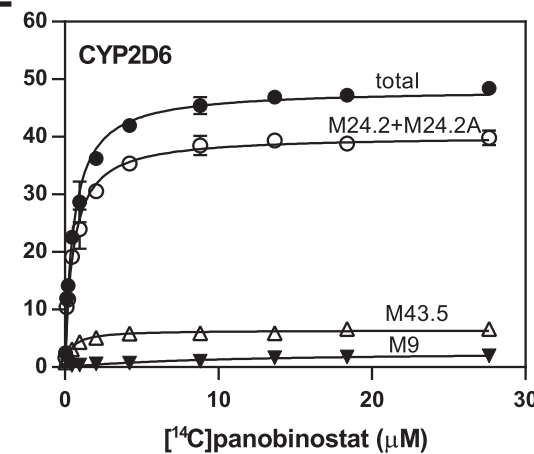

C

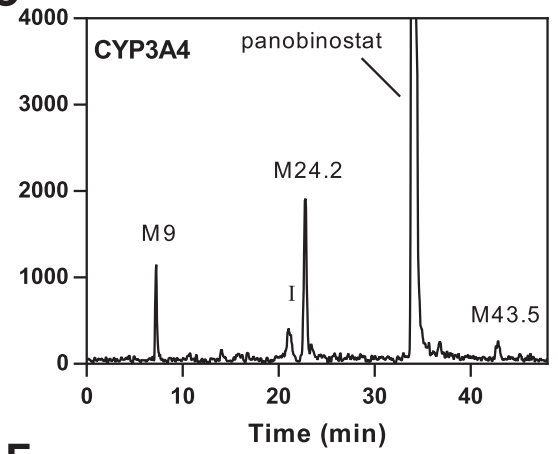

$\mathbf{F}$

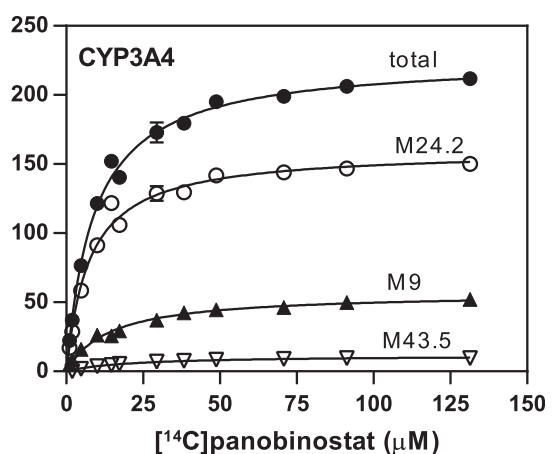

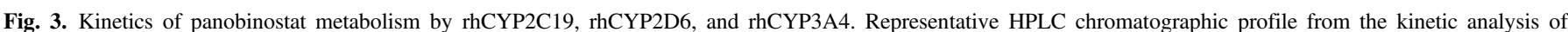

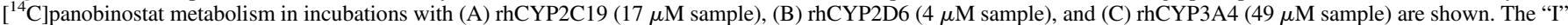

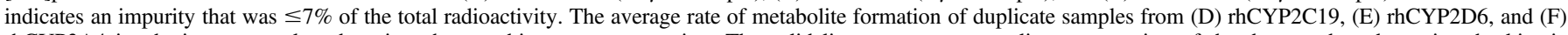

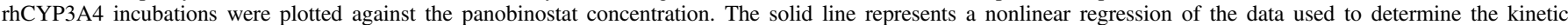
parameters, and the error bars indicate the range of the duplicate samples. 
TABLE 5

Clinically observed and Simcyp [and GastroPlus] model-predicted pharmacokinetic parameters of panobinostat after a single oral dose

\begin{tabular}{|c|c|c|c|c|c|c|c|}
\hline \multirow{2}{*}{ PK Parameter } & \multirow{2}{*}{ Study } & \multicolumn{6}{|c|}{ Dose } \\
\hline & & $15 \mathrm{mg}$ & $20 \mathrm{mg}$ & $30 \mathrm{mg}$ & $40 \mathrm{mg}$ & $60 \mathrm{mg}$ & $80 \mathrm{mg}$ \\
\hline \multirow[t]{3}{*}{$N$} & B2101 & 3 & 36 & 31 & & 4 & \\
\hline & B2102 & & 9 & 18 & 24 & 53 & 18 \\
\hline & Simulated & 100 & 100 & 100 & 100 & 100 & 100 \\
\hline \multirow[t]{4}{*}{$C_{\max }(\mathrm{ng} / \mathrm{ml})$} & B2101 & $12.2(65)$ & $23.6(57)$ & $34.0(56)$ & & $55.4(40)$ & \\
\hline & B2102 & & $19.5(61)$ & $39.8(69)$ & $58(59)$ & $66.9(70)$ & $63.5(58)$ \\
\hline & Simulated & $14.6(146)$ & $19.5(146)[31]^{\mathrm{a}}$ & $29.2(146)[47.5]$ & 39.1 (146) [58.9] & $58.8(146)$ & $78.7(146)$ \\
\hline & $\mathrm{PE}(\%)^{\mathrm{b}}$ & +20 & 0 to $-17[+31$ to +59$]$ & -27 to $--14[+19$ to +40$]$ & $-33[+2]$ & -12 to +6 & +24 \\
\hline \multirow[t]{4}{*}{$\mathrm{AUC}_{0-48} \mathrm{ng} \times \mathrm{h} / \mathrm{ml}$} & B2101 & $\mathrm{n} / \mathrm{a}$ & $198(48)$ & $262(49)$ & & $390(28)$ & \\
\hline & B2102 & & $131(58)$ & $310(117)$ & $299(76)$ & $330(62)$ & $342(54)$ \\
\hline & Simulated & $96.5(87)$ & $129(87)[151]$ & $195(88)[231]$ & $262(88)[280]$ & $398(88)$ & $538(89)$ \\
\hline & $\mathrm{PE}(\%)$ & & -2 to $-35[-24$ to +15$]$ & -37 to $-26[-25$ to -12$]$ & $-12[-6]$ & +2 to +21 & +57 \\
\hline \multirow{4}{*}{$\mathrm{T}_{\max }^{c}(\mathrm{~h})$} & B2101 & $1(0.5-2)$ & $1(0.5-4.5)$ & $1(0.5-8)$ & & & \\
\hline & B2102 & & $2.1(0.5-3.1)$ & $1(0.5-28)$ & $0.8(0.5-3.1)$ & $1(0.5-45.7)$ & $1(0.5-6)$ \\
\hline & Simulated & $1.3(0.3-1.8)$ & $1.3(0.3-1.8)[1.28]$ & $1.3(0.3-1.8)[1.28]$ & $1.3(0.3-1.8)[1.28]$ & $1.3(0.3-1.8)$ & $1.3(0.3-1.8)$ \\
\hline & $\mathrm{PE}(\%)$ & +30 & -38 to $+30[-39$ to +28$]$ & $+30[+28]$ & $+63[+60]$ & +30 & +30 \\
\hline
\end{tabular}

$\mathrm{n} / \mathrm{a}$, not available.

${ }^{a}$ The simulated value in brackets is the predicted value and prediction error from GastroPlus of one simulated subject.

${ }^{b} \mathrm{PE}$, prediction error $(\%)=[$ (predicted-observed $) /$ observed $] \times 100$.

${ }^{c}$ Values are the median (range) for $\mathrm{T}_{\max }$ and arithmetic mean $(\mathrm{CV} \%)$ for all other parameters.

developed to incorporate $40 \%$ of the metabolic CL by CYP3A4. Based on the relative contributions of CYP2D6 and CYP2C19 with respect to CYP3A4 determined from the kinetic study, the contributions of these enzymes were entered as $12 \%$ and $3 \%$, respectively. This model was used to simulate the PK of panobinostat dosed orally (15-80 mg) as a single dose or multiple Monday, Wednesday, Friday doses for 2 weeks. The simulated PK parameters were compared with those from several clinical trials (Table 5, Table 6, and Table 7). The $C_{\max }$ and $T_{\max }$ values were predicted within $\sim 2$-fold of the observed value for both single and multiple doses. The AUC was also predicted within 2-fold for most trials, with the exception of the 60- and 80-mg doses in trial B2102, where the exposure was overpredicted (prediction errors of $+150 \%$ and $+183 \%$, respectively) (Table 6). The variability (CV\%) of the AUC values was predicted relatively well; however, the variability in the $C_{\max }$ values was overpredicted compared with the observed values. The variability in $C_{\max }$ was most sensitive to the $\mathrm{CV} \%$ entered for $V_{\mathrm{ss}}(15 \%)$ (Table 2). Evaluation of changes of the default CV\% (30\%) for absorption parameters $\left(f_{\mathrm{a}}, k_{\mathrm{a}}, Q_{\text {gut }}\right)$ or intrinsic clearance did not impact the variability in panobinostat $C_{\max }$ values (20-mg single-dose evaluated; data not shown). A reduction in the $V_{\mathrm{ss}} \mathrm{CV} \%$ from $15 \%$ to $8 \%$ resulted in a $\mathrm{CV} \%$ value closer to the actual variability in $C_{\max }$ (predicted $67 \%$ vs. actual $57 \%-61 \%$ for the $20-\mathrm{mg}$ single dose), as well as the CV\% for AUC (predicted 54\% vs. actual 48\%-58\%; data not shown). Representative concentration-time profiles of panobinostat after single and multiple 20-mg doses in patients are shown in Fig. 4.

Simulation of the Drug Interaction of Panobinostat with KTZ. The PBPK model was also built to capture the clinical DDI magnitude of the strong CYP3A4 inhibitor, KTZ. The model predicted the PK parameters of panobinostat $\left(C_{\max }\right.$ and AUC) in the absence or presence of KTZ within 2-fold of the actual values (Table 7). The geometric mean $C_{\max }$ and AUC ratios were also predicted well. The predicted and observed geometric mean $C_{\max }$ ratios were 1.7 and 1.6, respectively, and the AUC ratios were both 1.8. The concentration-time profiles of panobinostat in the absence and presence of KTZ are shown in Fig. 5.

Simulation of the Drug Interaction of Panobinostat with DEX. The PBPK model was verified to predict the weak interaction of DEX

TABLE 6

Clinically observed and Simcyp model-predicted PK parameters of panobinostat after three times a week (Monday, Wednesday, Friday) dosing for 2 weeks

\begin{tabular}{|c|c|c|c|c|c|c|c|}
\hline \multirow{2}{*}{ PK Parameter } & \multirow{2}{*}{ Study } & \multicolumn{6}{|c|}{ Dose } \\
\hline & & $15 \mathrm{mg}$ & $20 \mathrm{mg}$ & $30 \mathrm{mg}$ & $40 \mathrm{mg}$ & $60 \mathrm{mg}$ & $80 \mathrm{mg}$ \\
\hline \multirow{7}{*}{$C_{\max }(\mathrm{ng} / \mathrm{ml})$} & B2101 & 3 & 18 & 4 & & & \\
\hline & B2102 & & 8 & 12 & 22 & 17 & 4 \\
\hline & Simulated & 100 & 100 & 100 & 100 & 100 & 100 \\
\hline & B2101 & $13.2(58)$ & $28.8(62)$ & $17.3(61)$ & & & \\
\hline & B2102 & & $33.6(49)$ & $38.4(61)$ & $41.6(88)$ & $51.8(56)$ & $69.6(39)$ \\
\hline & Simulated & 16.7 (126) & $22.4(126)$ & 33.9 (126) & $45.6(126)$ & $69.6(126)$ & 94.2 (126) \\
\hline & $\mathrm{PE}(\%)^{\mathrm{a}}$ & +27 & -33 to -22 & -12 to +96 & +10 & +34 & +35 \\
\hline \multirow[t]{4}{*}{$\mathrm{AUC}_{0-48} \mathrm{ng} \times \mathrm{h} / \mathrm{ml}$} & B2101 & $149(48)$ & $264(56)$ & $235(62)$ & & & \\
\hline & B2102 & & $245(87)$ & $280(59)$ & 271 (59) & $306(50)$ & $369(52)$ \\
\hline & Simulated & $180(47)$ & $242(48)$ & $368(48)$ & $498(48)$ & 765 (48) & 1044 (49) \\
\hline & PE $(\%)$ & +21 & -8 to -1 & +31 to +57 & +84 & +150 & +183 \\
\hline \multirow[t]{4}{*}{$T_{\max }^{b}(\mathrm{~h})$} & B2101 & 1 & 1 & 2.1 & & & \\
\hline & B2102 & & $1(0.5-2.1)$ & $2(0.7-4.0)$ & $1.1(0.5-4.0)$ & $1.1(0.5-6.0)$ & $1.5(0.7-2.0)$ \\
\hline & Simulated & $1.3(0.3-1.7)$ & $1.3(0.3-1.8)$ & $1.3(0.3-1.8)$ & $1.3(0.3-1.7)$ & $1.3(0.3-1.8)$ & $1.3(0.3-1.8)$ \\
\hline & PE $(\%)$ & +30 & +30 & -38 to -35 & +18 & +18 & -13 \\
\hline
\end{tabular}

${ }^{a} \mathrm{PE}$, prediction error $(\%)=[$ (predicted-observed $) /$ observed $] \times 100$.

${ }^{b}$ Values are the median (range) for $T_{\max }$ and arithmetic mean (CV\%) for all other parameters. 
TABLE 7

Clinically observed and Simcyp model-predicted PK parameters of panobinostat administered as a single oral 20-mg single dose with (1 hour after fourth KTZ dose) and without KTZ $400 \mathrm{mg}$ orally dosed once a day for 5 days

\begin{tabular}{|c|c|c|c|c|}
\hline $\begin{array}{c}\text { PK } \\
\text { Parameter }^{a}\end{array}$ & & $\begin{array}{l}\text { Panobinostat } \\
\text { Alone }\end{array}$ & $\begin{array}{l}\text { Panobinostat } \\
\quad+\text { KTZ }\end{array}$ & $\begin{array}{l}\text { Geometric Mean } \\
\text { Ratio }(90 \% \mathrm{CI})\end{array}$ \\
\hline \multirow{3}{*}{$C_{\max } \mathrm{ng} / \mathrm{ml}$} & Observed $^{\mathrm{b}}(n=14)$ & $18.52(42.6)$ & $29.98(93.3)$ & $1.6(1.2-2.2)$ \\
\hline & Predicted $(n=100)$ & 9.67 (146) & $16.5(154)$ & $1.7(1.6-1.8)$ \\
\hline & Prediction error $(\%)^{\mathrm{c}}$ & -48 & -45 & 6 \\
\hline \multirow[t]{3}{*}{$\begin{array}{c}\mathrm{AUC}_{0-\infty} \mathrm{ng} \\
\quad \times \mathrm{h} / \mathrm{ml}\end{array}$} & $\begin{array}{l}\text { Observed } \\
\qquad(n=11-12)\end{array}$ & $133.0(39.9)$ & $220.7(54.6)$ & $1.8(1.5-2.2)$ \\
\hline & Predicted $(\mathrm{n}=100)$ & $225(48)$ & $401(48)$ & $1.8(1.7-1.9)$ \\
\hline & Prediction error (\%) & +69 & +82 & 0 \\
\hline
\end{tabular}

${ }^{a}$ Values are the geometric mean $(\mathrm{CV} \%)$.

${ }^{b}$ Observed values are from Hamberg et al. (2011).

${ }^{c}$ Prediction error $\%=[($ predicted-observed $) /$ observed $] \times 100$.

with panobinostat. The model input parameters and verification results for modeling DEX PK (20-mg single and multiple doses) and the weak clinical CYP3A4 induction with triazolam can be found in the supplemental materials. The results of the prediction of the interaction of DEX (20 mg) with panobinostat (20-mg Monday, Wednesday, Friday
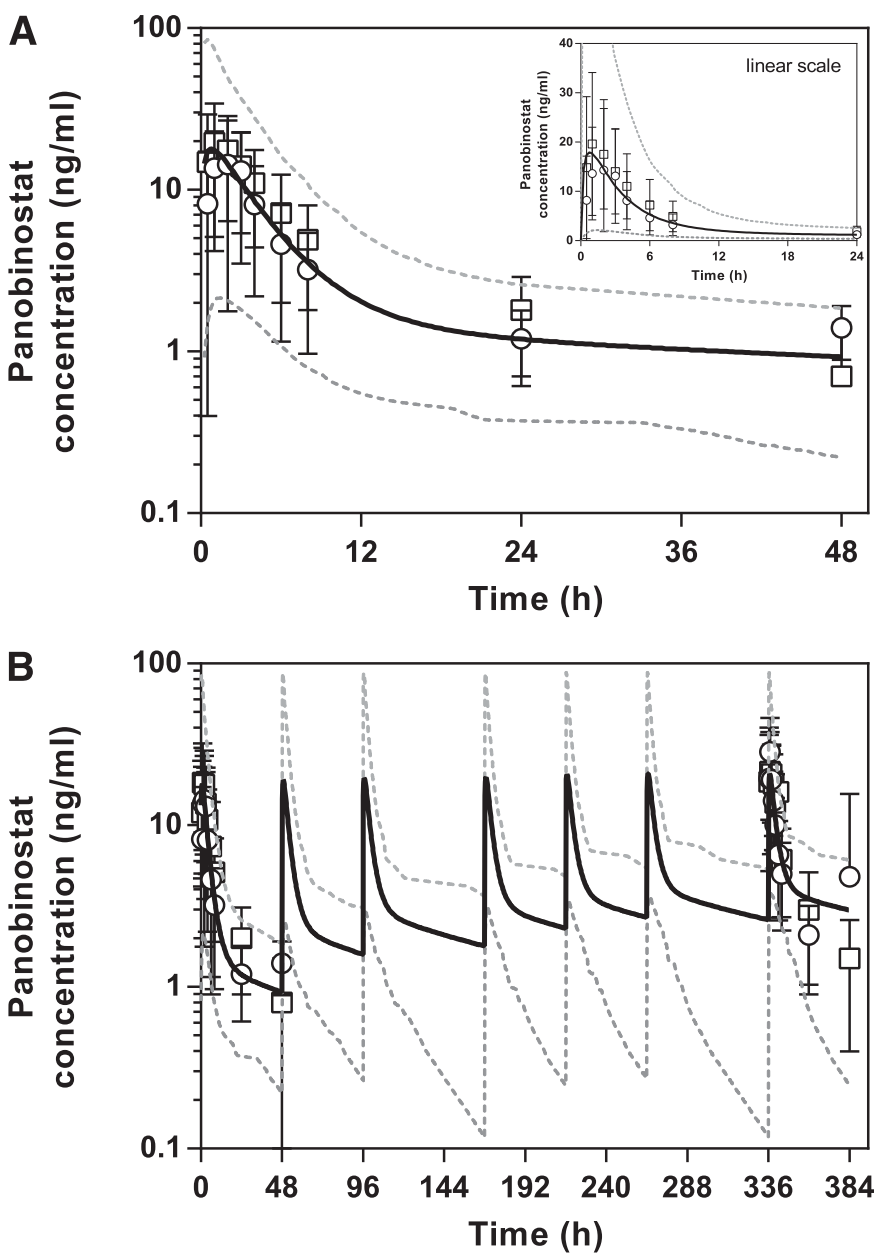

Fig. 4. Observed and predicted concentration-time profiles of a (A) single 20-mg oral dose of panobinostat or (B) multiple 20-mg oral doses (Monday, Wednesday, Friday) of panobinostat for 2 weeks. The solid black line represents the simulated concentration-time profiles of panobinostat, and the dotted lines are the 5th and 95th confidence intervals. The points on the graph are the observed mean concentrationtime data from trial CLBH589B2101 (squares) and CLBH589B2102 (circles) \pm S.D. (error bars).

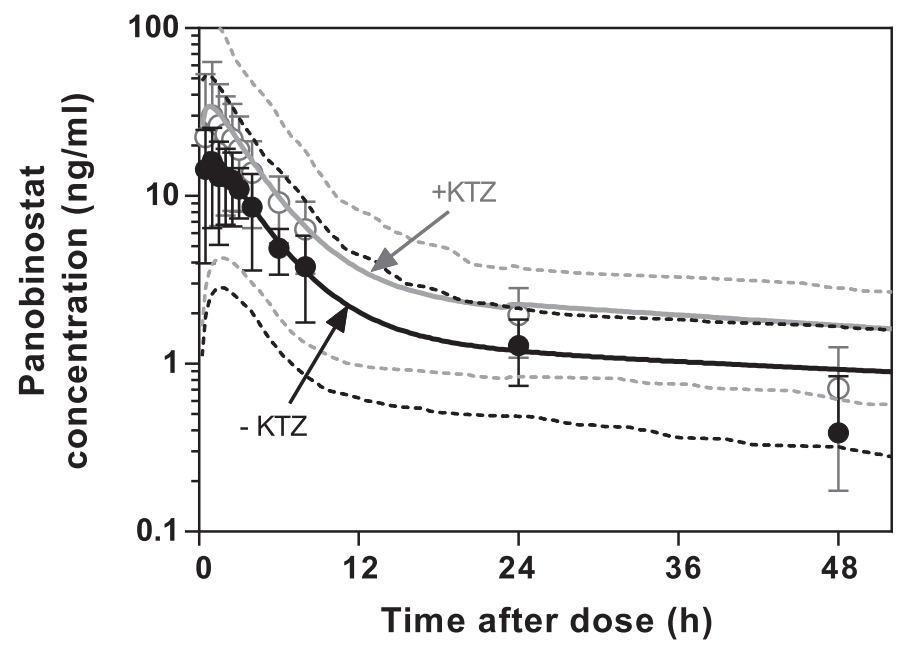

Fig. 5. Observed and predicted concentration-time profiles of panobinostat in the absence or presence of KTZ (400 mg), which was dosed once a day for 5 days. One hour after the third dose of KTZ, $20 \mathrm{mg}$ of panobinostat was administered, and concentrations of panobinostat were measured up to 48 hours. The solid black and gray lines represent the simulated mean concentration-time profiles of panobinostat in the absence and presence of KTZ, respectively. The corresponding dotted lines are the predicted 10th and 90th confidence intervals. The data points on the graphs are the observed mean \pm S.D. (error bars) of panobinostat plasma concentrations (Hamberg et al., 2011)

doses) are shown in Table 8. The predicted PK parameters were within 2 -fold of the actual values, and the AUC and $C_{\max }$ ratios were within the acceptable prediction criteria, as described in Guest et al. (2011).

Prediction of Panobinostat PK in the Presence of RIF. The model was then applied to predict the drug interaction of panobinostat with a strong CYP3A4 inducer, RIF, in lieu of an actual clinical trial. RIF (600 mg) was dosed once a day for 14 days, and a single dose of panobinostat $(20 \mathrm{mg})$ was given on day 7 . The results of the prediction are shown in Table 9, and the concentration-time profiles of panobinostat and RIF are shown in Fig. 6. The predicted geometric mean $C_{\max }$ and AUC ratios were 0.45 (55\% decrease in $\left.\mathrm{C}_{\max }\right)$ and 0.35 (65\% decrease in AUC), respectively. This original modeling was performed using Simcyp, version 13, where the RIF $\operatorname{Ind}_{\max }$ value (fold change with respect to the vehicle control) for CYP3A4 was 8 versus 16 in later versions of the software. A parameter sensitivity analysis of the RIF Ind $_{\text {max }}$ parameter on the panobinostat AUC ratio (using the Simcyp population representative) can be found in Supplemental Fig. 5. The predicted AUC ratio ranged from $0.32 \%$ to $0.14(68 \%-86 \%$ reduction in AUC) with RIF Ind max $_{\text {values of } 8-16 .}$

TABLE 8

Clinically observed and Simcyp model-predicted PK parameters of panobinostat on cycle 1 , day 8 (in the absence of DEX) and on cycle 2, day 8 (in the presence of DEX)

\begin{tabular}{|c|c|c|c|c|}
\hline $\begin{array}{c}\text { PK } \\
\text { Parameter }^{a}\end{array}$ & & $\begin{array}{l}\text { Panobinostat } \\
\text { Alone }\end{array}$ & $\begin{array}{l}\text { Panobinostat } \\
+ \text { DEX }\end{array}$ & $\begin{array}{l}\text { Geometric } \\
\text { Mean Ratio }\end{array}$ \\
\hline \multirow[t]{2}{*}{$\mathrm{C}_{\max } \mathrm{ng} / \mathrm{ml}$} & Observed $^{b}(n=12-15)$ & $9.5(60.4)$ & $8.1(90.3)$ & 0.85 \\
\hline & $\begin{array}{l}\text { Predicted }(n=100) \\
\text { Prediction error }(\%)^{c}\end{array}$ & 12.3 & 13.6 & 0.90 \\
\hline \multirow{2}{*}{$\begin{array}{c}\mathrm{AUC}_{0-24} \mathrm{ng} \\
\times \mathrm{h} / \mathrm{ml}\end{array}$} & Observed $(n=12-15)$ & $61.8(60.9)$ & $47.5(76.8)$ & 0.77 \\
\hline & $\begin{array}{l}\text { Predicted }(n=100) \\
\text { Prediction error }(\%)\end{array}$ & 117 & 99.3 & 0.85 \\
\hline
\end{tabular}

${ }^{a}$ Values are the geometric mean $(\mathrm{CV} \%)$.

${ }^{b}$ Observed values are from Mu et al. (2016) and San-Miguel et al. (2013).

${ }^{c}$ Prediction error $\%=[$ (predicted-observed $) /$ observed $] \times 100$. 
TABLE 9

Simcyp model-predicted PK parameters of panobinostat administered as a single oral 20-mg dose on day 7 with and without RIF $600 \mathrm{mg}$ orally dosed once a day for 14 days

\begin{tabular}{clccc}
\hline $\begin{array}{c}\text { PK } \\
\text { Parameter }^{a}\end{array}$ & $\begin{array}{c}\text { Panobinostat } \\
\text { Alone }\end{array}$ & $\begin{array}{c}\text { Panobinostat } \\
+ \text { RIF }\end{array}$ & $\begin{array}{c}\text { Geometric Mean } \\
\text { Ratio (90\% CI })\end{array}$ \\
\hline $\mathrm{C}_{\text {max }}{ }^{a} \mathrm{ng} / \mathrm{ml}$ & Predicted $(n=100)$ & $9.67(146)$ & $4.34(149)$ & $0.45(0.41-0.49)$ \\
$\mathrm{AUC}_{0-\infty} \mathrm{ng}$ & Predicted $(n=100)$ & $231(47)$ & $80.1(63)$ & $0.35(0.320-.38)$ \\
$\times \mathrm{h} / \mathrm{ml}$ & & & & \\
\hline
\end{tabular}

${ }^{a}$ Values are the geometric mean $(\mathrm{CV} \%)$.

Prediction of MDZ PK in the Presence of Panobinostat. Due to the in vitro CYP3A4 reversible and time-dependent inhibition properties of panobinostat, the drug interaction of panobinostat with the sensitive CYP3A4/5 substrate MDZ was predicted. Panobinostat $(20 \mathrm{mg})$ was dosed orally on Monday, Wednesday, and Friday for 2 weeks and a single 5-mg dose of MDZ was given on day 15 with the last dose of panobinostat. The results of the simulation are found in Table 10, and the concentration-time profiles of MDZ and panobinostat are shown in Fig. 7. The predicted geometric mean $C_{\max }$ and AUC ratios were both 1.04 .

Sensitivity Analysis of Select Panobinostat PBPK Model Input Parameters on the MDZ AUC Ratio. The design of the panobinostatMDZ trial simulation is as described in the preceding section. The range

A
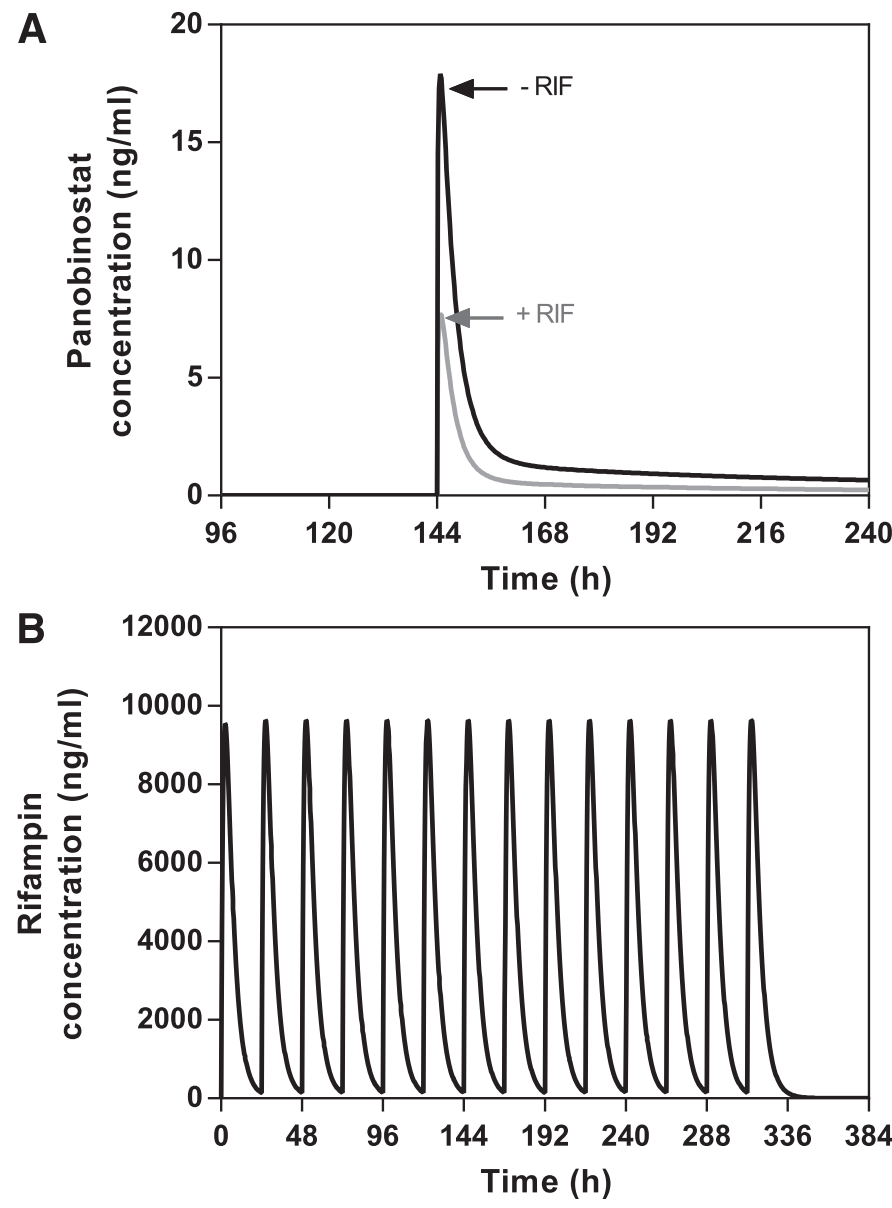

Fig. 6. Predicted concentration-time profile of panobinostat in the presence or absence of RIF. (A) The lines represent the simulated mean concentration-time profile of panobinostat (20-mg single dose on day 7) in the absence (black line) or presence (gray line) of RIF. (B) The solid black line represents the simulated mean concentration-time profile of RIF (600 mg daily for 14 days).
TABLE 10

Simcyp model-predicted pharmacokinetic parameters of MDZ administered as a single oral 5-mg dose on day 15 with and without multiple administration of panobinostat $20 \mathrm{mg}$ three times a week (Monday, Wednesday, Friday) for 2 weeks

\begin{tabular}{|c|c|c|c|c|}
\hline $\begin{array}{c}\text { PK } \\
\text { Parameter }^{a}\end{array}$ & & $\begin{array}{l}\text { MDZ } \\
\text { Alone }\end{array}$ & $\begin{array}{c}\text { MDZ+ } \\
\text { Panobinostat }\end{array}$ & $\begin{array}{c}\text { Geometric Mean } \\
\text { Ratio }(90 \% \mathrm{CI})\end{array}$ \\
\hline $\mathrm{C}_{\max } \mathrm{ng} / \mathrm{ml}$ & Predicted $(n=100)$ & $14.5(57)$ & $15.1(56)$ & $\begin{array}{c}1.04 \\
(1.03-1.04)\end{array}$ \\
\hline $\begin{array}{c}\mathrm{AUC}_{0-\infty} \mathrm{ng} \\
\times \mathrm{h} / \mathrm{ml}\end{array}$ & Predicted $(n=100)$ & $56.2(64)$ & 58.7 (64) & $\begin{array}{c}1.04 \\
(1.04-1.05)\end{array}$ \\
\hline
\end{tabular}

${ }^{a}$ Values are the geometric mean $(\mathrm{CV} \%)$.

of the parameter values chosen for the sensitivity analysis is described in the Materials and Methods section and encompassed the S.D. of experimentally determined CYP3A4 time-dependent inactivation parameters for panaobinostat $\left(k_{\text {inact }}, K_{\mathrm{I}}\right)$ or an arbitrary 10-fold range (panobinostat $k_{\mathrm{a}}$, hepatic CYP3A4 $k_{\mathrm{deg}}$, and panobinostat $K_{\mathrm{i}}$ for CYP3A4 reversible inhibition). The results of the sensitivity analysis can be found in Fig. 8. Variation of the $K_{\mathrm{I}}$ or $k_{\text {inact }}$ value separately (Fig. $8 \mathrm{~A}$ and $\mathrm{B}$ ) or together (Fig. 8C) was not impactful to the MDZ AUC ratio (AUC ratio $<1.1$ ). The panobinostat $k_{\mathrm{a}}$ value or CYP3A4 hepatic $k_{\mathrm{deg}}$

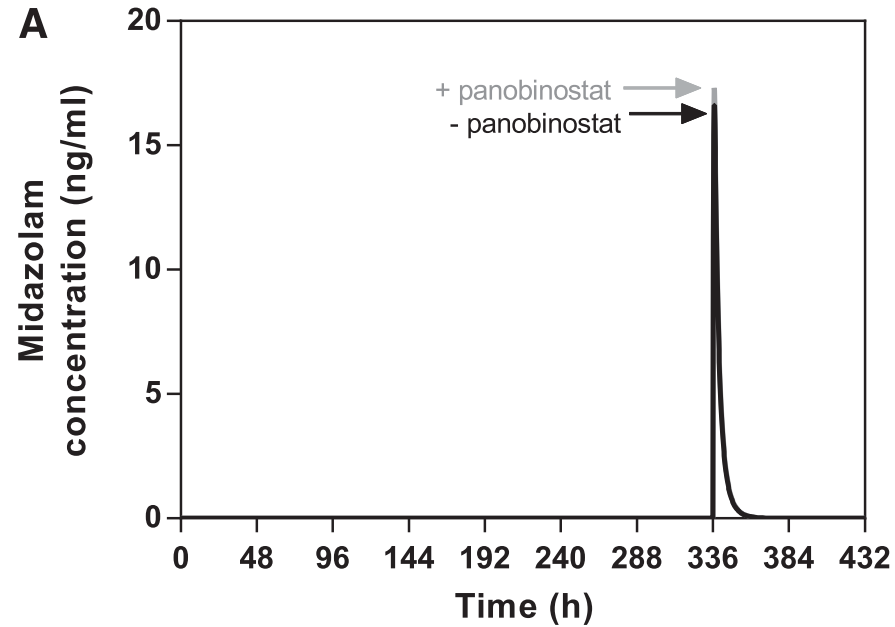

B

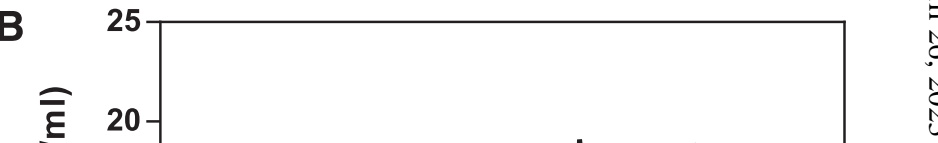
Fig. 7. Predicted concentration-time profile of $\mathrm{MDZ}$ in the presence or absence of panobinostat. (A) The lines represent the mean simulated concentration-time profile line) of panobinostat. (B) The solid black line represents the simulated concentration-time profile of panobinostat $(20 \mathrm{mg}$ dosed weekly on Monday, Wednesday, Friday). 
A
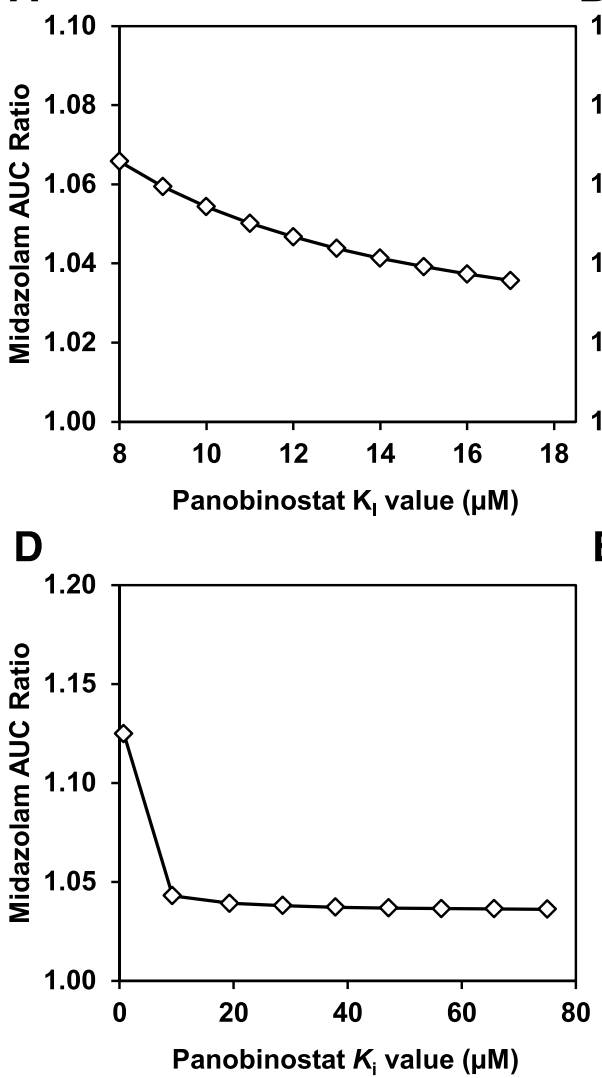

B

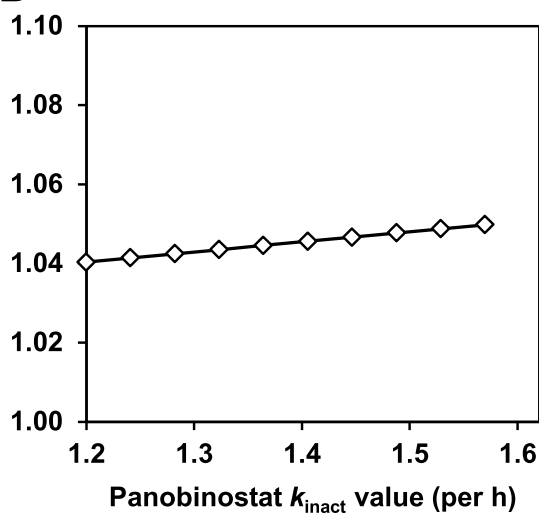

E

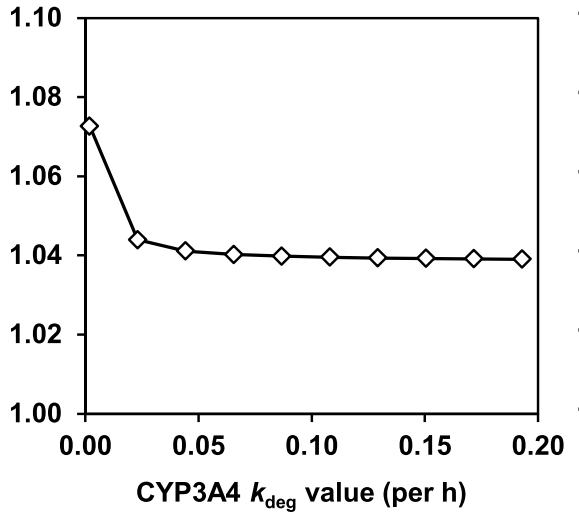

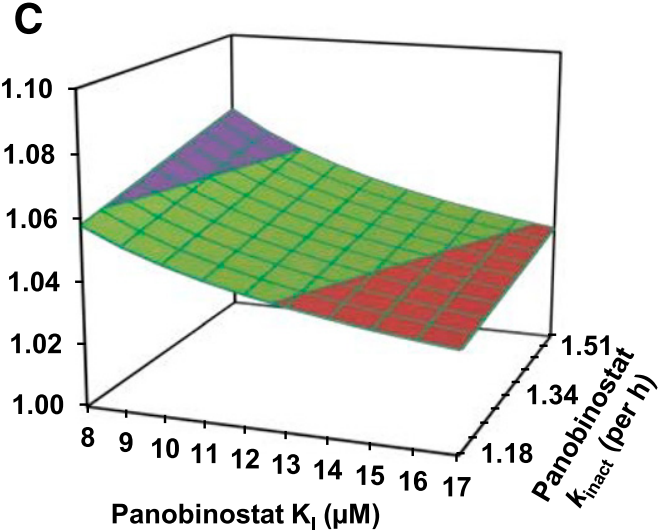

Panobinostat $K_{1}(\mu M)$

$\mathbf{F}$

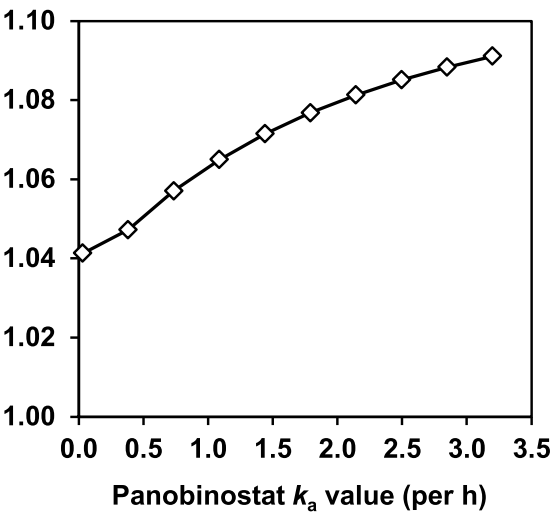

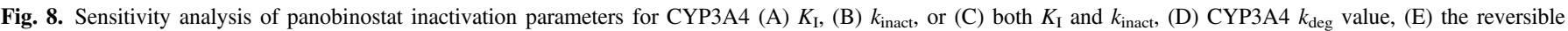
CYP3A4 inhibition constant, $K_{\mathrm{i}}$, and (F) the panobinostat $k_{\mathrm{a}}$ value on the predicted AUC ratio of MDZ in the presence of panobinostat.

value (Fig. $8 \mathrm{D}$ and $\mathrm{F}$ ) was also not sensitive to the DDI effect on MDZ. A reduction in the $K_{\mathrm{i}}$ value for CYP3A4 to $0.75 \mu \mathrm{M}$ (10 times lower than actual) increased the AUC ratio to slightly over 1.1.

\section{Panobinostat GastroPlus ACAT Modeling}

Using the established ACAT absorption model for panobinostat in humans, the PK profiles after a single oral dose of 20,30 , and $40 \mathrm{mg}$ of panobinostat were simulated. The observed and predicted PK parameters of each simulation are summarized in Table 5 (values in parentheses). The projected panobinostat absorption in humans was $\sim 100 \%$ within the dose range of $20-40 \mathrm{mg}$. The predicted $T_{\max }, C_{\max }$, and $\mathrm{AUC}_{0-48 \mathrm{~h}}$ values were similar to the corresponding observed values. The similarity between the observed and the projected PK profiles and parameters suggest that ACAT absorption model for panobinostat was qualified. Sensitivity analysis on the stomach $\mathrm{pH}$ ranging from 0.5 to 8.0 was therefore performed. Figure 9 presents the absorption of $20 \mathrm{mg}$ of panobinostat with stomach $\mathrm{pH}$ in a range of $0.5-8.0$. The predicted absorption was $\sim 100 \%$ for this range of $\mathrm{pH}$ values.

\section{Discussion}

The use of PBPK modeling in drug development and ultimately in regulatory submissions has become increasingly apparent from the literature and recent product labels (Zhao et al., 2011, 2012; Huang and Rowland, 2012; Huang et al., 2013; Jones et al., 2015; Jamei 2016). PBPK models are particularly important for evaluating the potential consequences of intrinsic (e.g., human physiology, genetics) and extrinsic factors (e.g., coadministration of other drugs) on the exposure of the drug in different tissues, organs, and in the systemic circulation.
With well qualified PBPK models for the intended modeling purpose, predictions can be made for untested or difficult-to-test clinical scenarios and can be particularly useful for dosing recommendations. Particularly in the case of Farydak, it was undesirable to expose patients to subtherapeutic levels of panobinostat as would occur in the presence of strong CYP3A4 inducers. Therefore, the PBPK modeling and simulation work presented here were influential for the dosing strategy with respect to coadministration of panobinostat with strong CYP3A4

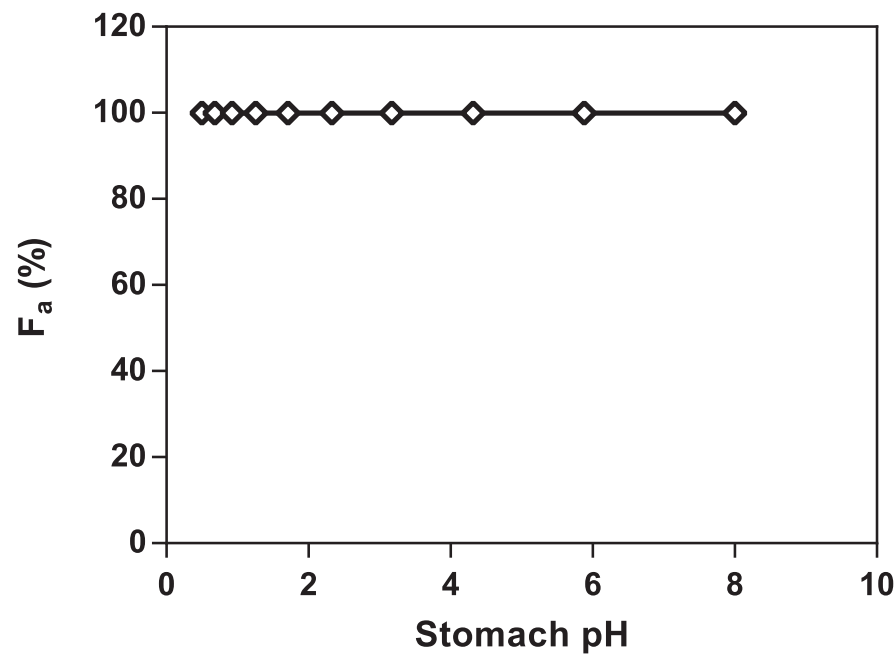

Fig. 9. PBPK model-projected absorption of panobinostat $(20 \mathrm{mg})$ versus stomach $\mathrm{pH}$ in humans. 
inducers, as well as sensitive substrates of CYP3A4/5 in lieu of actual clinical trials.

Results from the in vitro assays presented here found panobinostat not likely to be a clinical inducer of major drug-metabolizing P450 enzymes; however, was found to be a reversible in vitro inhibitor of CYP2D6 and a weaker inhibitor of CYP3A4/5 and CYP2C19. A clinical DDI study investigating the potential magnitude of effect of panobinostat on the CYP2D6 substrate, dextromethorphan, was therefore run and reported in Feld et al. (2013). Panobinostat (20 mg dosed every other day for 3 days) increased dextromethorphan exposure by $64 \%$, indicating that panobinostat is a weak CYP2D6 inhibitor in vivo. The observed mean panobinostat $C_{\max }$ value in the clinical DDI study was $25.8 \mathrm{ng} / \mathrm{ml}(0.074 \mu \mathrm{M})$. As mentioned in the previous article, based on the empirical equation, $1+[\mathrm{I}] /$ $K_{\mathrm{i}}$, the AUC ratio was predicted to be 1.4; therefore, a clinical inhibition of CYP2D6 by panobinostat was expected in this study (Feld et al., 2013). Since initiation of this clinical DDI trial, regulatory guidance has described the use of more mechanistic models, including PBPK, rather than empirical methods, to assess the risk of drug interaction potential and decisions regarding whether clinical DDI studies may be warranted (http:// www.fda.gov/downloads/drugs/guidancecomplianceregulatoryinformation/ guidances/ucm292362.pdf, http://www.ema.europa.eu/docs/en_GB/ document_library/Scientific_guideline/2012/07/WC500129606.pdf). These types of models, which incorporate time-varying concentrations of both the perpetrator and victim drug and time-dependent effects of $\mathrm{P} 450$ inhibition and induction, offer better prediction outcomes (Einolf 2007).

A PBPK model for panobinostat was developed to describe singleand multiple- (Monday, Wednesday, Friday) dose PK and the magnitude of drug interaction with KTZ. The model incorporated the reversible and time-dependent $\mathrm{P} 450$ inhibition properties of panobinostat, as well as the relative contributions of CYP3A4, CYP2D6, and CYP2C19 to the total oxidative $\mathrm{CL}$ of panobinostat in humans. The relative contributions of these individual P450 enzymes in humans were determined by both in vitro scaling of rhP450 kinetic data and scaling "top-down" using the results of the KTZ DDI study (which defined the approximate contribution of CYP3A4). The relative contributions of the individual $\mathrm{P} 450$ enzymes determined in vitro were scaled to humans in vivo based on the $\sim 40 \%$ contribution of CYP3A4 to panobinostat CL in humans determined from the KTZ DDI study (Hamberg et al., 2011) with confirmation of the extent of $\mathrm{P} 450$-mediated oxidative metabolism from the human ADME study (Clive et al., 2012). The resultant contributions of CYP3A4, CYP2D6, and CYP2C19 to the total in vivo CL panobinostat were estimated to be $40 \%, 12 \%$, and $3 \%$, respectively. Additional CL pathways in humans, such as reduction, hydrolysis, and glucuronidation, were grouped together in the model to equate to the remainder of total panobinostat CL.

This PBPK model appropriately predicted the PK parameters of panobinostat over the dose range of $10-80 \mathrm{mg}$, with most parameters predicted within 2-fold of the actual value. In the single-dose trials (Fig. 4A; Table 5) the model predicted the $C_{\max }$ and $\mathrm{AUC}_{0-48 \mathrm{~h}}$ values within a prediction error of $-33 \%$ to $+24 \%$ and $-35 \%$ to $+57 \%$, respectively. In the multiple-dose study (Fig. 4B; Table 6), for trials B2101 and B2102, the prediction error was within 2-fold for $C_{\max }$ at all doses and AUC up to the 40-mg dose. A higher prediction error was seen with the prediction of AUC at higher doses (60 and $80 \mathrm{mg}$ ) in trial B2102 (prediction error of $+150 \%$ and $+183 \%)$.

Importantly, this PBPK model was able to simulate the clinical DDI of panobinostat $\left(C_{\max }\right.$ and AUC ratios) with KTZ, which established the contribution of CYP3A4 to total panobinostat CL in the model (Fig. 5; Table 7). The relative contribution of the other P450 enzymes (i.e., CYP2D6 and CYP2C19) remain to be verified clinically; however, their contributions are expected to be low and likely do not warrant any further investigation as complete inhibition of one of these enzymes is not expected to increase panobinostat exposure by more than $\sim 14 \%$. The interindividual variability in CL was reported to be higher at $74 \%$ (Savelieva et al., 2015).

With verification of the PBPK model to predict panobinostat PK and DDI with KTZ and DEX, we predicted the effect of multiple 600-mg daily doses of RIF on panobinostat PK. Based on the results of the PBPK modeling, coadministration with strong inducers of CYP3A4 are to be avoided when taking Farydak as a result of the predicted (at least) 65\% reduction in exposure (Fig. 6; Table 9). The reference to this modeling and simulation data in support of the labeling recommendation is present in the FDA-approved product label (Farydak prescribing information, 2016). PBPK modeling is particularly useful in cases like this, where there is no benefit to patients, especially cancer patients, exposed to subtherapeutic levels of an investigational drug when mechanistically evaluating the effect of a strong inducer. Particularly for RIF, PBPK modeling has been found to be predictive of drug interactions with respect to CYP3A4 induction especially if the $\mathrm{fm}_{\mathrm{CYP} 3 \mathrm{~A} 4}$ for the victim drug clearance has been defined appropriately (Almond et al., 2016; Wagner et al., 2016). If the role of CYP3A4 for the victim drug has been properly defined by in vitro and in vivo methods (e.g., clinical inhibition with a strong CYP3A4 inhibitor), modeling and simulation can be used to predict the effect of induction with qualified inducer models.

Particularly in the case of time-dependent CYP3A4 inhibition, modeling time-dependent effects, such as time-varying concentrations of perpetrator in the liver and intestine, as well as the actual clinical dosing regimen (e.g., Monday, Wednesday, Friday dosing), are important to capture in the prediction model. Based on the PBPK modeling, panobinostat is expected to increase the exposure (i.e., AUC) of the sensitive CYP3A4 substrate MDZ by only 1.04-fold (Fig. 7; Table 10) (i.e., $<10 \%$, as stated in the FDA Farydak product label (https://www.pharma.us.novartis.com/sites/www.pharma.us.novartis.com /files/farydak.pdf). This implies that there will be little, if any, effect of panobinostat when co-administered with CYP3A4/5-cleared substrates. In contrast, the EMA product label (http://www.ema.europa.eu/ docs/en_GB/document_library/EPAR_-_Product_Information/human/ 003725/WC500193298.pdf) or (http://www.ema.europa.eu/docs/ en_GB/document_library/EPAR_-_Risk-management-plan_summary/ human/003725/WC500188847.pdf) do not mention PBPK modeling results for panobinostat with sensitive CYP3A4/5 substrates, although the modeling is acknowledged (http://www.ema.europa.eu/docs/ en_GB/document_library/EPAR_-_Public_assessment_report/human/ 003725/WC500193300.pdf), it did not appear to influence the EMA product label).

Although panobinostat has $\mathrm{pH}$-dependent solubility, overall, more than $16 \mathrm{mg}$ of drug substance can be fully dissolved in a $\mathrm{pH}$ range of 1.2-7.6. Given its high permeability, relatively good solubility and low dose level $(20 \mathrm{mg})$, the PBPK model predicts that elevated gastric $\mathrm{pH}$ would not impact panobinostat absorption in humans (Fig. 9). This implies that coadministration with agents that increase the $\mathrm{pH}$ in the stomach (antacids, $\mathrm{H}_{2}$ receptor antagonists, and proton-pump inhibitors) is not likely to affect the exposure of panobinostat in patients. It is noteworthy that the potential prolongation on gastrointestinal transit time by proton pump inhibitors (Rasmussen et al., 1997) is not considered in the panobinostat ACAT model. Figure 9 shows complete absorption of a $20 \mathrm{mg}$ of panobinostat in humans, suggesting that further increase on gastrointestinal transit time would not result in higher absorption. The simulation result is presented in Farydak drug label (Farydak prescribing information, 2016) in lieu of clinical study. In a recent publication, results of GastroPlus modeling found a signification correlation of model predicted AUC and $C_{\max }$ ratios with clinical DDI observations of compounds known to have pH-dependent DDI (Zhu et al., 2016). 
Recently, an alectinib GastroPlus ACAT model predicted that gastric $\mathrm{pH}$ changes would not affect alectinib exposure, and the absorption modeling was included in the new drug application to FDA to successfully replace clinical assessment study (Parrott et al., 2016).

In conclusion, PBPK models were developed to predict the DDI of panobinostat as a victim and perpetrator of CYP3A4, as well as pH-dependent DDI. This modeling was incorporated into the FDAapproved product label for Farydak, providing information to aid in dosing recommendations for coadministration with other drugs. This work exemplifies how PBPK modeling can improve efficiency in clinical drug development, aiding in the decisions whether dedicated mechanistic clinical DDI trials are necessary, particularly in consideration of the well being of patients.

\section{Acknowledgments}

We thank the following colleagues from Novartis (East Hanover, NJ) for advice and support of this work: Grazyna Ciszewska, Lawrence Jones, Amy Wu, and Tapan Ray for synthesis of $\left[{ }^{14} \mathrm{C}\right]$ panobinostat and Mu Song from Oncology Clinical Pharmacology.

\section{Authorship Contributions}

Participated in research design: Einolf, Lin, Won, Gu, He, Mangold.

Conducted experiments: Einolf, Lin, Won, Wang, Chun, Gu.

Performed data analysis: Einolf, Lin, Won, Wang, Chun, Gu, He, Mangold.

Wrote or contributed to the writing of the manuscript: Einolf, Lin.

\section{References}

Almond LM, Mukadam S, Gardner I, Okialda K, Wong S, Hatley O, Tay S, Rowland-Yeo K, Jamei M, Rostami-Hodjegan A, et al. (2016) Prediction of drug-drug interactions arising from CYP3A induction using a physiologically based dynamic model. Drug Metab Dispos 44: 821-832.

Cheng T, Grasse L, Shah J, and Chandra J (2015) Panobinostat, a pan-histone deacetylase inhibitor: rationale for and application to treatment of multiple myeloma. Drugs Today (Barc) 51:491-504

Clive S, Woo MM, Nydam T, Kelly L, Squier M, and Kagan M (2012) Characterizing the disposition, metabolism, and excretion of an orally active pan-deacetylase inhibitor, panobinostat, via trace radiolabeled $14 \mathrm{C}$ material in advanced cancer patients. Cancer Chemother Pharmacol 70:513-522.

DeAngelo DJ, Spencer A, Bhalla KN, Prince HM, Fischer T, Kindler T, Giles FJ, Scott JW, Parker K, Liu A, et al. (2013) Phase Ia/II, two-arm, open-label, dose-escalation study of oral panobinostat administered via two dosing schedules in patients with advanced hematologic malignancies. Leukemia 27:1628-1636.

Einolf HJ (2007) Comparison of different approaches to predict metabolic drug-drug interactions. Xenobiotica 37:1257-1294.

Feld R, Woo MM, Leighl N, Shepherd FA, Beck JT, Zhao L, Gazi L, Hengelage T, Porro MG, and Nayak A (2013) A clinical investigation of inhibitory effect of panobinostat on CYP2D6 substrate in patients with advanced cancer. Cancer Chemother Pharmacol 72 : $747-755$.

Flarakos J, Du Y, Bedman T, Al-Share Q, Jordaan P, Chandra P, Albrecht D, Wang L, Gu H Einolf HJ, et al. (2016) Disposition and metabolism of $\left[\left({ }^{14)} \mathrm{C}\right]\right.$ Sacubitril/Valsartan (formerly LCZ696) an angiotensin receptor neprilysin inhibitor, in healthy subjects. Xenobiotica 46 986-1000.

Flipo M, Charton J, Hocine A, Dassonneville S, Deprez B, and Deprez-Poulain R (2009) Hydroxamates: relationships between structure and plasma stability. J Med Chem 52:6790-6802. Garnock-Jones KP (2015) Panobinostat: first global approval. Drugs 75:695-704.
Guest EJ, Aarons L, Houston JB, Rostami-Hodjegan A, and Galetin A (2011) Critique of the twofold measure of prediction success for ratios: application for the assessment of drug-drug interactions. Drug Metab Dispos 39:170-173.

Hamberg P, Woo MM, Chen LC, Verweij J, Porro MG, Zhao L, Li W, van der Biessen D, Sharma S, Hengelage T, et al. (2011) Effect of ketoconazole-mediated CYP3A4 inhibition on clinical pharmacokinetics of panobinostat (LBH589), an orally active histone deacetylase inhibitor. Cancer Chemother Pharmacol 68:805-813.

Huang SM, Abernethy DR, Wang Y, Zhao P, and Zineh I (2013) The utility of modeling and simulation in drug development and regulatory review. J Pharm Sci 102:2912-2923.

Huang SM and Rowland M (2012) The role of physiologically based pharmacokinetic modeling in regulatory review. Clin Pharmacol Ther 91:542-549.

Jamei M (2016) Recent advances in development and application of Physiologically-Based Pharmacokinetic (PBPK) models: a transition from academic curiosity to regulatory acceptance. Curr Pharmacol Rep 2:161-169.

Jones HM, Chen Y, Gibson C, Heimbach T, Parrott N, Peters SA, Snoeys J, Upreti VV, Zheng M, and Hall SD (2015) Physiologically based pharmacokinetic modeling in drug discovery and development: a pharmaceutical industry perspective. Clin Pharmacol Ther 97:247-262.

Mu S, Kuroda Y, Shibayama H, Hino M, Tajima T, Corrado C, Lin R, Waldron E, Binlich F, and Suzuki K (2016) Panobinostat PK/PD profile in combination with bortezomib and dexamethasone in patients with relapsed and relapsed/refractory multiple myeloma. Eur J Clin Pharmacol 72:153-161.

Obach RS, Walsky RL, and Venkatakrishnan K (2007) Mechanism-based inactivation of human cytochrome p450 enzymes and the prediction of drug-drug interactions. Drug Metab Dispos 35 246-255.

Parrott NJ, Yu LJ, Takano R, Nakamura M, and Morcos PN (2016) Physiologically based absorption modeling to explore the impact of food and gastric $\mathrm{pH}$ changes on the pharmacokinetics of alectinib. AAPS J 18:1464-1474.

Rasmussen L, Qvist N, Oster-Jørgensen E, Rehfeld JF, Holst JJ, and Pedersen SA (1997) A doubleblind placebo-controlled study on the effects of omeprazole on gut hormone secretion and gastric emptying rate. Scand J Gastroenterol 32:900-905.

Rostami-Hodjegan A and Tucker GT (2002) The effects of portal shunts on intestinal cytochrome P450 3A activity. Hepatology 35:1549-1550, author reply 1550-1551.

Sager JE, Yu J, Ragueneau-Majlessi I, and Isoherranen N (2015) Physiologically based Pharmacokinetic (PBPK) modeling and simulation approaches: a systematic review of published models, applications, and model verification. Drug Metab Dispos 43:1823-1837.

San-Miguel JF, Richardson PG, Günther A, Sezer O, Siegel D, Bladé J, LeBlanc R, Sutherland H, Sopala M, Mishra KK, et al. (2013) Phase Ib study of panobinostat and bortezomib in relapsed or relapsed and refractory multiple myeloma. J Clin Oncol 31:3696-3703.

Savelieva M, Woo MM, Schran H, Mu S, Nedelman J, and Capdeville R (2015) Population pharmacokinetics of intravenous and oral panobinostat in patients with hematologic and solid tumors. Eur J Clin Pharmacol 71:663-672.

Shapiro GI, Frank R, Dandamudi UB, Hengelage T, Zhao L, Gazi L, Porro MG, Woo MM, and Lewis LD (2012) The effect of food on the bioavailability of panobinostat, an orally active pan-histone deacetylase inhibitor, in patients with advanced cancer. Cancer Chemother Pharmacol 69:555-562.

Shou M, Hayashi M, Pan Y, Xu Y, Morrissey K, Xu L, and Skiles GL (2008) Modeling, prediction, and in vitro in vivo correlation of CYP3A4 induction. Drug Metab Dispos 36: 2355-2370.

Wagner C, Pan Y, Hsu V, Sinha V, and Zhao P (2016) Predicting the effect of CYP3A inducers on the pharmacokinetics of substrate drugs using physiologically based pharmacokinetic (PBPK) modeling: An analysis of PBPK submissions to the US FDA. Clin Pharmacokinet 55:475-483.

Zhao P, Rowland M, and Huang SM (2012) Best practice in the use of physiologically based pharmacokinetic modeling and simulation to address clinical pharmacology regulatory questions. Clin Pharmacol Ther 92:17-20.

Zhao P, Zhang L, Grillo JA, Liu Q, Bullock JM, Moon YJ, Song P, Brar SS, Madabushi R, Wu TC et al. (2011) Applications of physiologically based pharmacokinetic (PBPK) modeling and simulation during regulatory review. Clin Pharmacol Ther 89:259-267.

Zhu AZ, Ho MD, Gemski CK, Chuang BC, Liao M, and Xia CQ (2016) Utilizing in vitro dissolution-permeation chamber for the quantitative prediction of pH-dependent drug-drug interactions with acid-reducing agents: a comparison with physiologically based pharmacokinetic modeling. AAPS J 18:1512-1523.

Address correspondence to: Dr. Heidi J. Einolf, Novartis, One Health Plaza, East Hanover, NJ 07936. E-mail: heidi.einolf@novartis.com 